\title{
Alteraciones en fagocitos mononucleares: un viraje al significado de la muerte de monocitos y macrófagos en la inmunopatogénesis de la tuberculosis
}

\begin{abstract}
Diana Castaño', Mauricio Rojas²
1 Grupo de Inmunología Celular e Inmunogenética, Facultad de Medicina, Universidad de Antioquia, Medellín, Colombia.

2 Instituto de Investigaciones Médicas, Grupo de Inmunología Celular e Inmunogenética, Unidad de Citometría de Flujo, Facultad de Medicina. Universidad de Antioquia, Medellín, Colombia.

Los fagocitos mononucleares, en particular los monocitos y los macrófagos, han sido considerados los blancos primarios de la infección por Mycobacterium tuberculosis y, a su vez, las principales células efectoras y reservorios de la micobacteria. La heterogeneidad de estas células, así como su plasticidad, hacen que las respuestas ante la infección sean diversas y complejas. Las diferencias que presentan los fagocitos mononucleares de animales naturalmente resistentes a la infección, la expresión de los genes asociados al control de las infecciones micobacterianas y las discrepancias que se observan entre los monocitos en circulación de los pacientes con tuberculosis y los controles sanos en la expresión de CD14, CD36 y HLA-DR, así como en la muerte celular, nos ha sugerido que puede haber alteraciones en la distribución de las subpoblaciones de monocitos o en su estado de madurez.

En humanos, las subpoblaciones de monocitos de sangre periférica se definieron inicialmente de acuerdo con la expresión de las moléculas de superficie CD14 y CD16. Hay dos tipos principales de monocitos, unos con alta expresión de CD14 y carentes de CD16 (CD14 ${ }^{+}$CD16 $^{-}$) y otros con baja expresión de CD14 y que expresan CD16 (CD14+CD16 $\left.{ }^{+}\right)$.

En los pacientes con tuberculosis hay alteraciones en los recuentos de las subpoblaciones de monocitos, lo que nos hace considerar que el entendimiento de estos eventos podría ser fundamental en la comprensión de la inmunopatogénesis de esta enfermedad.
\end{abstract}

Palabras clave: monocito, macrófago, subpoblaciones de monocitos, apoptosis, necrosis, Mycobacterium tuberculosis.

Alterations in mononuclear phagocytes: improving the significance of monocyte and macrophage death in the immunopathogenesis of tuberculosis

Mononuclear phagocytes, particularly monocytes and macrophages, have been considered the primary targets of infection by Mycobacterium tuberculosis and, at the same time, the main effector cells and reservoirs of mycobacteria. The heterogeneity of these cells and their plasticity, make diverse and complex the responses against the infection. The differences in mononuclear phagocytes responses in animals, the expression of genes associated with natural resistance to infection, and the discrepancy between circulating monocytes from patients with tuberculosis and healthy controls in the expression of CD14, CD36 and HLA-DR, and cell death, have suggested changes in the distribution of monocyte subpopulations or in their state of maturity.

In humans, subpopulations of peripheral blood monocytes were defined according to the expression of surface molecules CD14 and CD16. There are two main types of monocytes, a group with high expression of CD14 that does not express CD16 (CD14 ${ }^{+}$DD16) and others with low expression of CD14, expressing CD16 $\left(\mathrm{CD} 14^{+} \mathrm{CD} 16^{+}\right)$. In tuberculosis patients there are alterations in the counts of these subpopulations, which lead us to consider that these alterations could be capital phenomenon to understand the immunopathogenesis of this disease.

Key words: monocyte, macrophage, monocyte subsets, apoptosis, necrosis, Mycobacterium tuberculosis.

Correspondencia:

Mauricio Rojas, Carrera 53 № 61-30, Laboratorio 420, Sede de Investigación Universitaria, Universidad de Antioquia, Medellín, Colombia.

Teléfono: (574) 219 6461; fax: (574) 2196463

mrojasl@une.net.com
Heterogeneidad y plasticidad de los fagocitos mononucleares

Antes de entrar a definir el papel de los fagocitos mononucleares en la infección por Mycobacterium tuberculosis, es conveniente hacer una revisión 
general de estas células. El sistema fagocítico mononuclear está lleno de contrastes funcionales y morfológicos, pero indiscutiblemente, juega un papel preponderante en las infecciones intracelulares y en la respuesta inmunitaria innata (1). Su heterogeneidad, plasticidad, capacidad efectora, vínculo determinante entre la inmunidad innata y la adaptativa, así como su potencial regulador, hacen de los fagocitos mononucleares un sistema difícil de dimensionar (2).

Elie Metchnikoff, premio nobel de Fisiología y Medicina en 1908, fue el primero en describir y clasificar a los macrófagos en 1880, y se le atribuye la primera representación de los macrófagos en el año de 1892. Describió a los fagocitos como un conjunto de "células con capacidad de ingerir y digerir partículas". Más tarde, las catalogó como glóbulos blancos y "les atribuyó un papel determinante como células partícipes de la primera línea de defensa contra las infecciones de los seres vivos" (3).

El alemán Karl Albert Ludwig Aschoff (4) introdujo la expresión "sistema retículo-endotelial" desde 1924. Este sistema abarcaba un grupo de células con capacidad de ingerir un colorante vital que, Aschoff asumió, resultaba de la fagocitosis. A dicho sistema pertenecían los monocitos, los macrófagos, los histiocitos, las células reticulares, los neumocitos (macrófagos tisulares estacionarios), los fibroblastos y las células endoteliales.

Sin embargo, debido a que este sistema no se adaptaba ni explicaba el conocimiento que se había generado en años posteriores de los fagocitos mononucleares, en 1969 (5), se definió la expresión "sistema fagocítico mononuclear. Este grupo de células se agruparon con base en su alta capacidad de fagocitar y similitudes en morfología, función y origen. En este sistema se incluyen los monocitos, los macrófagos y sus precursores en la médula ósea. Estas células proceden de un precursor común CD45+ CD34 ${ }^{+}$. Como consecuencia la expresión "sistema retículoendotelial" entró en desuso.

No obstante, el sistema fagocítico mononuclear necesita una redefinición de sus conceptos (2) ya que se sabe que los monocitos y los macrófagos también se originan en el hígado fetal. Existen precursores tempranos comunes a la línea monocítica, la granulocítica y la linfocítica y se sabe que las células dendríticas mieloides se diferencian a partir de monocitos. A pesar que no existe un consenso claro al respecto, varios autores consideran, en la actualidad, a las células dendríticas como parte del sistema fagocítico mononuclear $(6,7)$. En esta revisión nos referiremos esencialmente a los monocitos y a los macrófagos, unos de los principales componentes en la defensa frente a $M$. tuberculosis y unos de los tipos celulares en los que más se evidencia la heterogeneidad de la respuesta inmune.

Aunque las células del sistema fagocítico mononuclear son definidas precisamente por su capacidad de fagocitosis, siguen siendo muy heterogéneas entre sí. La heterogeneidad de los macrófagos se puede apreciar en las variaciones de la morfología (el diámetro, la granularidad, la forma y la estructura, entre otros), del fenotipo de marcadores de membrana, del contenido de organelas y de las respuestas funcionales (8). Esta variabilidad se cree que obedece a las diversas localizaciones anatómicas, al estado de maduración y diferenciación y al tipo de activación que reciben estos fagocitos (2) (figura 1). La diversidad de las funciones "efectoras" y la variación de sus respuestas y fenotipos cuando colonizan diferentes tejidos, son sólo algunas de las "ventanas" por las que se puede apreciar la altísima heterogeneidad de estas células.

Los monocitos se forman en la médula ósea a partir de células pluripotenciales de la serie granulocítica-monocítica. En esta evolución el factor de crecimiento GM-CSF (granulocyte macrophage colony stimulating factor), el M-CSF y otras citocinas, como la interleucina 3 (IL-3), juegan un papel indispensable $(9,10)$. Cuando estos factores de crecimiento están presentes en la médula ósea, la célula progenitora prolifera y se diferencia a promonocito. Los promonocitos permanecen en la médula ósea menos de 24 horas, completan su maduración y después pasan a la circulación sanguínea como monocitos.

En esta etapa los monocitos se visualizan al microscopio en extendidos de sangre periférica, como células de mayor tamaño que los linfocitos, cuyo diámetro oscila entre 15 y $30 \mu \mathrm{m}$, con una relación núcleo/citoplasma alta y en una proporción de $1 \%$ a $6 \%$ en un recuento normal de leucocitos. En los adultos sanos la vida media de un monocito circulante se estima en 70 horas, luego de las cuales, salen de los capilares sanguíneos y se localizan en los tejidos, donde se diferencian hacia macrófagos o hacia células dendríticas $(2,11)$. No es completamente claro cómo se regula la conversión hacia macrófagos in vivo y se desconoce que 


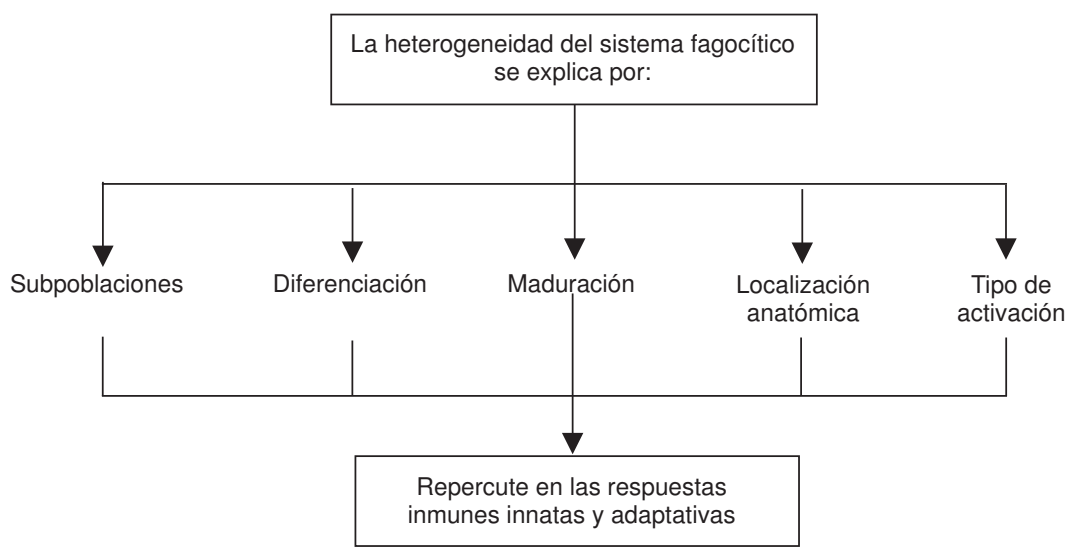

Figura 1. La heterogeneidad de los fagocitos mononucleares. La variabilidad y plasticidad del sistema fagocito-mononuclear se explica por las diversas subpoblaciones que existen de estas células, por los diferentes estados de maduración y de diferenciación en los cuales se pueden encontrar, por las múltiples localizaciones anatómicas de estos fagocitos y por las diferentes formas de activación estas células que pueden recibir. Cada una de las variables expuestas debe influir en las respuestas funcionales de los fagocitos mononucleares como parte del sistema inmune innato y como moduladores del sistema inmunitario adaptativo.

tan "idóneas" son para ejecutar sus respuestas efectoras cuando llegan a los tejidos. Durante la diferenciación de monocitos hacia macrófagos el tamaño se incrementa entre 5 y 10 veces (10), hay aumento del número de los gránulos intracelulares, e incremento de la complejidad, la capacidad fagocítica y la producción de enzimas líticas. Los macrófagostienen mayorexpresióndelasmoléculas del complejo mayor de histocompatibilidad y de las moléculas coestimuladoras.

Tradicionalmente, se ha sugerido que las fluctuaciones en los conteos de leucocitos de sangre periférica se deben a un incremento en la actividad de la médula ósea, que conlleva a la liberación de los precursores requeridos para la colonización de la lesión inflamatoria y que obedecen a diversas señales como la producción de quimiocinas (como la fractalcina y la proteína quimioatrayente del monocito 1, MCP1), mediadores proinflamatorios (como proteínas del complemento, histamina, etc.) u otras señales paracrinas que no se han elucidado por completo $(1,8)$.

El aumento del conteo de leucocitos se corresponde con la migración y la colonización del tejido afectado por parte de los fagocitos mononucleares. Muchos de los estudios que evalúan las respuestas funcionales de los fagocitos mononucleares se basan en la obtención de macrófagos a partir de exudados peritoneales de ratones tratados con tioglicolato o polietilenglicol más adyuvantes (12). Estos tratamientos ponen un velo al estudio de los hechos que ocurren durante la metamorfosis de la célula inmadura a efectora, ya que se ha descrito que no todos los fagocitos migran hacia la cavidad peritoneal en respuesta al polietilenglicol $(13,14)$. En ratones, la obtención y la diferenciación in vitro de los precursores de la médula ósea permite estudiar las células con cierta homogeneidad; pero, aun en estos casos, hay evidencias de heterogeneidad en marcadores fenotípicos entre clonas obtenidas a partir de una misma médula (15), aunque en presencia del factor estimulante de colonias 1 (CSF-1) se reduce dicha heterogeneidad (16).

Otro aspecto que revela la heterogeneidad y la plasticidad de los fagocitos mononucleares es el descubrimientodeunapoblacióndecélulasprimitivas denominada derivados pluripotanciales de los monocitos (monocyte-derived multipotential cells, $M O M C$ ), que sugiere la naturaleza pluripotencial de algunos de los monocitos circulantes (17). Estas células tienen una morfología de fibroblasto y un fenotipo único positivo para CD14 (correceptor para los lipopolisacáridos bacterianos, junto con el receptor tipo toll 4 y MD-2), CD45 (antígeno panleucocitario y fosfatasa de tirosinas), CD34 (proteína transmembrana y molécula de adhesión importante en las interacciones célula-célula, y con la matriz extracelular). Además, la CD34 pertenece a la familia de las sialomucinas que se expresa en el tejido hematopoyético y vascular; estás células también expresan un receptor para colágeno tipo I (17).

Los MOMC se pueden obtener en un cultivo de 7 a 10 días de células mononucleares de sangre periférica sobre matrices de fibronectina, en presencia de suero bovino fetal como fuente de 
factores de crecimiento. Entre los MOMC hay progenitores con capacidad de diferenciarse en una variedad de células no fagocíticas que van a poblar huesos, cartílagos, tejido adiposo, músculo esquelético y cardíaco, neuronas y el endotelio, lo que indica que los monocitos circulantes son más pluripotenciales de lo que se pensaba.

En la actualidad, se han empezado a sugerir terapias de trasplante de monocitos circulantes como método potencial para la regeneración de tejidos (17).

\section{Reconocimiento, fagocitosis y maduración del fagosoma que contiene Mycobacterium tuberculosis}

La infección por M. tuberculosis empieza usualmente en los sacos alveolares del sistema respiratorio. Estos compartimentos y los intersticios que limitan los espacios alveolares, son ricos en macrófagos y en células epiteliales tipo II. Ambos tipos de células se consideran que son uno de los blancos tempranos de la infección porque entran en contacto directo con $M$. tuberculosis o con sus productos (18). Las micobacterias inhaladas pueden interactuar con estas células a través de varios receptores fagocíticos y no fagocíticos (figura 2). Entre los primeros, y bajo condiciones de no opsonización, se incluyen los receptores de manosa, de complemento (CR1, CR2, CR3 y CR4), los de la proteína surfactante y los receptores tipo scavenger, entre otros (19). En condiciones de opsonización, se incluye una pléyade de moléculas capaces de reconocer complejos formados por anticuerpos (receptores Fc) y proteínas del complemento. Algunos autores clasifican dentro de este grupo al receptor que interactúa con la proteína surfactante, ya que la consideran una proteína de opsonización (20). Entre los receptores no fagocíticos, están el CD14 y los toll-like receptors (TLR), los cuales juegan un papel crítico en la red de señalización para la activación de las respuestas innatas de los macrófagos (21).

M. tuberculosis ingresa a los fagocitos mononucleares a través de una endocitosis mediada por receptores fagocíticos, la cual induce el concomitante rearreglo del citoesqueleto de actina, que, finalmente, permiten la formación de un compartimiento de la membrana denominado fagosoma (22). Para degradar los microorganismos interiorizados, estos fagosomas deben madurar a compartimientos ácidos e hidrolíticos. Este proceso es muy regulado y se da mediante una serie de fusiones y fisiones complejas de estas estructuras con la red endosómica (endosomas tempranos, endosomas tardíos) y, finalmente, con los lisosomas (formando fagolisosomas) (23).

La habilidad de la micobacteria de persistir y replicarse dentro de los macrófagos del huésped se considera un hecho clave para el desarrollo de la tuberculosis. Este fenómeno se explica por una combinación de factores que produce la micobacteria y que regulan las respuestas efectoras de los fagocitos mononucleares como la secreción de enzimas que contrarrestan los

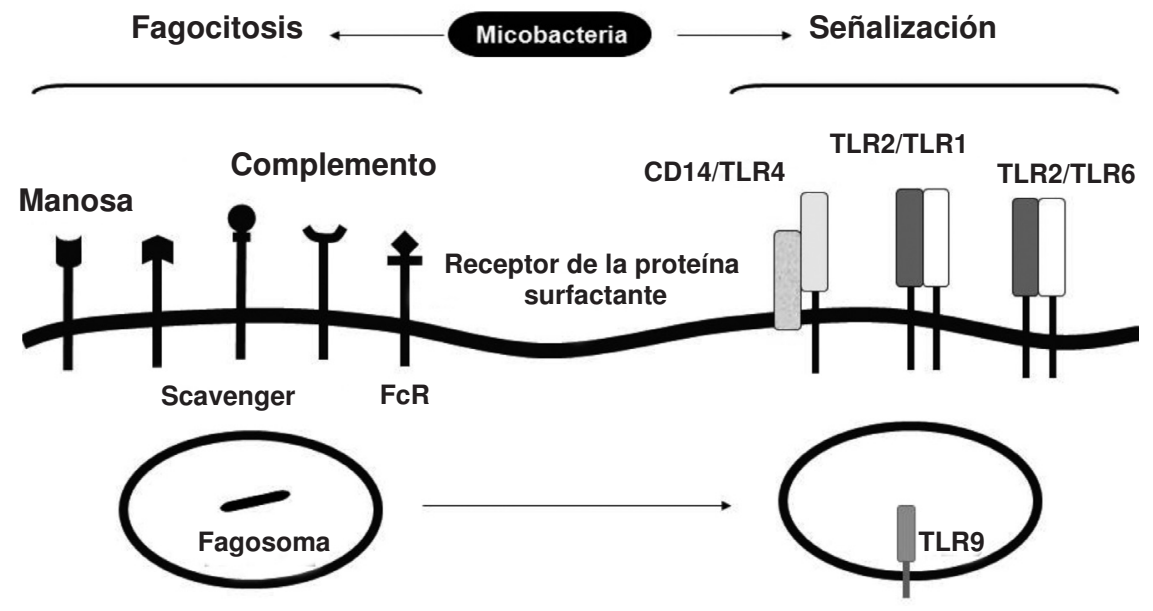

Figura 2. Las micobacterias son reconocidas por receptores que median su fagocitosis o la activación del fagocito mononuclear. Se hace una representación de algunos de los receptores fagocíticos (manosa, scavenger, complemento, de anticuerpos -FcR-, proteína surfactante) y no fagocíticos (CD14/TLR4, TLR2/1, TLR2/6, TLR9) que se han descrito como ligandos de diferentes componentes de la micobacteria. 
radicales derivados del oxígeno y del nitrógeno de los fagosomas $(24,25)$ (figura 3 ). Se ha descrito la liberación de derivados del fofatidil inositol manóido desde el fagolisoma que pueden afectar el estado de activación del macrófago (26) porque antagonizan la respuesta a citocinas, como el factor de necrosis tumoral alfa (TNFa), el interferón gamma (IFN $\gamma$ ), la IL-12 y la IL-1 $\beta$, al inducir un fenotipo compatible con los macrófagos activados alternativamente (1).

Se ha demostrado ampliamente que la formación del fagosolisosoma es uno de los principales blancos de la infección (27-29). La micobacteria bloquea estos fagosomas y lisosomas en las etapas tempranas de su maduración $(30,31)$ y se han asociado múltiples mecanismos moleculares con dicho bloqueo. Uno de estos mecanismos es el posicionamiento cercano de la micobacteria a la membrana de los fagosomas. Se ha demostrado que en ausencia de esta cercanía microscópica, por ejemplo, cuando se fagocitan agregados micobacterianos o en ausencia de colesterol, estos compartimientos maduran a fagolisosomas derivados de vacuolas autofágicas $(32,33)$.

Además, se ha reportado que diferentes componentes derivados de la pared micobacteriana tienen la capacidad de inhibir la maduración del fago- lisosoma, como la trehalosa multiacilada, el lipoarabinomanano y los derivados del fosfatilinositol-manósido que afectan la vía de la cinasa del fosfatidil-inositol 3 (phosphoinositide 3-kinases, PI3K) y, en general, el tráfico de membranas (3438). El lipoarabinomanano manósido (ManLAM), un componente estructural de la pared micobacteriana, considerado como uno de los principales factores de virulencia micobacteriana, ocasiona la detención de la maduración del fagosoma. EI ManLAM de $M$. tuberculosis virulentas, pero no de micobacterias no virulentas (AraLAM), bloquea la movilización del calcio $\left(\mathrm{Ca}^{+2}\right)$ del citosol (39). El $\mathrm{Ca}^{+2}$ es necesario para la cascada de señalización de la calmodulina y de la cinasa del fosfatidil-inositol 3 clase III (PI3K-III o hVPS34), esenciales para la producción de fosfato de PI3 $\left(\mathrm{PIP}_{3}\right)$ en los fagosomas. EI $\mathrm{PIP}_{3}$ junto con Rab5 son sustratos para la unión del EEA-1 (early endosome antigen 1), el cual es un regulador de la fusión de los fagosomas tempranos con el sistema de recirculación de endosomas tardíos y lisosomas (40). La interferencia del ManLAM con esta vía de señalización, así como la hidrólisis constante del $\mathrm{PIP}_{3}$ del fagosoma, catalizada por la fosfatasa de lípidos SapM (37) y asegura la residencia de $M$. tuberculosis en las vacuolas de los macrófagos, fenómeno que a largo plazo puede llevar a latencia (37).

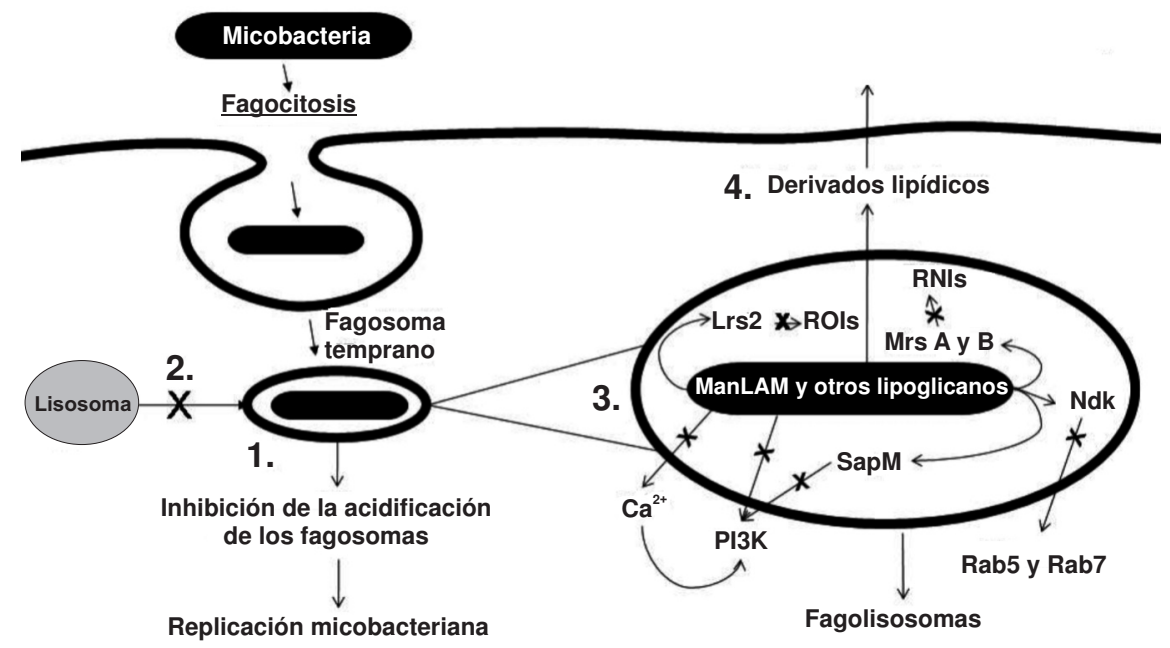

Figura 3. Factores producidos por la micobacteria para regular las respuestas efectoras de los fagocitos mononucleares. Se muestran diferentes vías que son blanco de la infección micobacteriana. 1) El cercano posicionamiento de la micobacteria junto a la membrana del fagosoma. 2) La inhibición de la maduración de los fagosomas a compartimientos ácidos por el bloqueo en la fusión con endosomas tardíos y lisosomas. 3) Diferentes componentes de la micobacteria que modulan el microambiente del fagosoma, brindan un ambiente favorable para su supervivencia y replicación. La bacteria libera enzimas como la Lrs2 y las Mrs A y B que inhiben los radicales intermediarios del oxígeno y de nitrógeno, respectivamente. El ManLAM antagoniza el calcio $\left(\mathrm{Ca}^{2+}\right)$ e inhibe la activación de la PI3K, la enzima Ndk que desactiva a Rab5 y Rab7 y la enzima SapM que hidroliza a PI3K. 4) Además, se conoce que la micobacteria libera diferentes lipoglucanos desde el fagosoma, los cuales desvían las respuestas de los macrófagos hacia una activación alternativa. 
Rab5 y Rab7, miembros de la superfamilia de proteínas pequeñas unidoras de GTP, Ras, controlan las interacciones secuenciales de los endosomas tempranos y tardíos con los fagosomas. Mientras que Rab5 se expresa sólo en endosomas tempranos, Rab7 se expresa en compartimientos endocitarios tardíos (41). Recientemente se ha demostrado que la cinasa Ndk liberada por $M$. tuberculosis desde los fagosomas, es una proteína inactivadora de Rab5 y Rab7, que lleva a la inhibición de la maduración del fagosoma $(42,43)$. Por lo tanto, se puede apreciar que las micobacterias utilizan diferentes estrategias para asegurar su sobrevida y para permitir el establecimiento de la infección micobacteriana.

\section{Muerte celular inducida por Mycobacterium tuberculosis H37Rv}

Una de las consecuencias de la interacción entre los macrófagos y las micobacterias es la inducción de la muerte de estas células hospederas (44) entre las que se han identificado: la apoptosis y la necrosis. La apoptosis es un tipo de muerte celular altamente regulado, principalmente por la activación de caspasas (cysteine-aspartic acid proteases) que desencadenan una cascada de reacciones catalíticas que escinden varias proteínas, entre ellas las mismas caspasas y otras esenciales para la actividad celular, produciendo cambios funcionales y morfológicos característicos (45). La necrosis, también conocida como oncosis, es un tipo de muerte celular caracterizado por un agotamiento abrupto de las reservas de ATP que causan una pérdida de la permeabilidad selectiva de la membrana citoplasmática, que lleva a la muerte celular por una lisis osmótica o por la actividad de lipasas sobre la membrana celular (46).

Además del redundante sistema de reconocimiento y de las alteraciones en la maduración de los fagosomas y en la señalización del calcio, nuestros estudios con líneas celulares y monocitos humanos han demostrado que la infección con $M$. tuberculosis H37Rv o la exposición al derivado proteico purificado (Purified Protein Derivative, PPD) de la micobacteria induce apoptosis de los fagocitos mononucleares (47-49). En células congénicas de ratón para el gen Slc11a1 (anteriormente designado como gen Nramp1), los macrófagos que controlan más eficientemente (resistentes, $\mathrm{B} 10 \mathrm{R}$, en el caso de las líneas celulares derivadas de médula ósea y $\mathrm{Nramp1}^{+/+}$, cepa $129 / \mathrm{sv}$, en el caso de los macrófagos peritoneales) in vitro el crecimiento de la micobacteria, sufren más apoptosis durante la infección con $M$. tuberculosis que los que no controlan la infección (susceptibles, B10S, Nramp1 ${ }^{-1}$, cepa 129/sv), lo cual sugiere una relación entre la muerte celular y el control de la micobacteria. Para asegurarse que, efectivamente, el tipo de muerte celular era apoptosis, se utilizaron diferentes técnicas tales como la fragmentación del ADN empleando geles de agarosa, la hipoploidía mediante la tinción del ADN con yoduro de propidio y el ensayo del TUNEL (terminal dUTP nick end labeling) para evaluar los quiebres monocatenarios en el ADN (39,50-53).

Líneas celulares de macrófagos congénicos de ratón para el gen Slc11a1 (50-53) y macrófagos peritoneales obtenidos de animales resistentes y susceptibles (52) fueron objeto de diferentes aproximaciones experimentales a fin de establecer la asociación entre los mecanismos involucrados en la inducción de apoptosis y el control de la micobacteria. Se demostró que la inhibición del crecimiento intracelular de $M$. tuberculosis H37Rv se correlacionaba con la producción de óxido nítrico (50-53). Los macrófagos del acervo resistente producen más óxido nítrico y son más propensos a sufrir apoptosis que los susceptibles después de la exposición a M. tuberculosis H37Rv vivo o al PPD.

Dado que se vislumbraba un circuito entre la activación de mecanismos efectores contra la micobacteria y la apoptosis, se estudiaron cuáles elementos reconocidos como moduladores de la respuesta del macrófago podrían estar involucrados en la inducción de muerte. La apoptosis estuvo asociada con la producción del TNFa y de óxido nítrico (NO), ya que los anticuerpos monoclonales para bloquear el TNFa e inhibidores competitivos de la sintasa 2 inducible de óxido nítrico (NOS2), como la aminoguanidina (AMG) y la $\mathrm{N}^{\mathrm{G}}$-monometil-L-arginina, inhibieron la producción de NO y la apoptosis (54). Con el fin de establecer si la inducción de apoptosis requiere el concurso de la micobacteria metabólicamente activa, determinamos la muerte celular por la exposición a M. tuberculosis inactivado por calor o al ManLAM. Observamos que no sólo no indujeron apoptosis sino que inhibieron la inducida por el PPD $(50,52,55)$. Sin embargo, esta inhibición se dio en presencia de NO, lo cual sugiere que esta molécula no era el único efector de la muerte celular $(50,52)$.

Hemos encontrado que durante la infección con $M$. tuberculosis hay activación de la caspasa $1(50,56)$. 
Ciertamente, el bloqueo de la producción del NO con AMG y de la caspasa 1 con el péptido antagonista que se une irreversiblemente a las formas activas de caspasa 1 (Tir-Val-Ala-Asp-aciloxi-metilcetona), independientemente retardaron la apoptosis inducida por M. tuberculosis (52) pero el bloqueo simultáneo de ambas vías previno la apoptosis. Esto sugirió un posible sinergismo entre las actividades de la caspasa 1 y el NO durante esta apoptosis y evidenció la existencia de mecanismos redundantes en los macrófagos para garantizar la eliminación del nicho requerido para la replicación micobacteriana (52).

Dada la existencia de más de un mecanismo en la muerte celular de los macrófagos, se quiso explorar la participación de otros efectores solubles. Se midieron las proporciones de células productoras de citocinas IL-1 $\beta$, IL-6, IL-10, IL-12 y TNFa y se observó esencialmente que la producción del TNFa e IL-10 contrastaban entre los macrófagos de acervo resistente y susceptible $(39,52)$. En respuesta a la infección con $M$. tuberculosis y al tratamiento con PPD hubo mayor proporción de macrófagos $\mathrm{B} 10 \mathrm{R}$ que producían TNFa que IL10 , y en el caso de los B10S se observó mayor porcentaje de macrófagos que producían IL-10 que TNFa $(39,50,52)$. De forma notable, la estimulación con el ManLAM indujo a los macrófagos de ambos acervos a producir IL-10, dando mayor relevancia a que esta citocina es capaz de inhibir la apoptosis de los macrófagos al promover la conservación del nicho de la micobateria $(39,52)$.

Dada la asociación encontrada entre la muerte celular y la producción de TNFa e IL-10, empezamos a determinar el papel de estas citocinas en la modulación de la apoptosis inducida por M. tuberculosis. Una de las primeras evidencias indicó que estas citocinas tienen función autocrina sobre su producción, dado que el tratamiento con anti-TNFa incrementaba la proporción de células productoras de IL-10, inhibía la apoptosis, disminuía la producción de NO, el número de células p53+, la activación de la caspasa 1 y prevenía la regulación negativa del Bcl-2 inducida por M. tuberculosis.

Por otro lado, el tratamiento con anti-IL-10 aumentaba las células $\mathrm{TNFa}^{+}$, la activación de la caspasa 1, el número de células p53+, aunque el incremento que se observó en el NO no fue significativo (52).

Para verificar si se requería el concurso de la micobacteria en la inducción de la muerte celular, se hicieron tratamientos con citocinas recombinantes. El tratamiento de células $\mathrm{B} 10 \mathrm{R}$ y B10S con mrTNFa, en ausencia de infección, indujo la misma proporción de apoptosis en ambas líneas celulares, y ésta se logró revertir con mrlL-10 en una forma dependiente de la dosis, con la concomitante inhibición de la producción de NO y la activación de caspasa 1 (52). Estos resultados sugirieron que el gen Slc11a1 afectaba el balance TNFa/IL-10 durante la infección con $M$. tuberculosis y, como consecuencia, la inducción de apoptosis de estos macrófagos. No obstante, el TNFa y la IL-10 tuvieron los mismos efectos sobre las células B10R y B10S. Se concluyó que ambas líneas celulares pueden responder a estímulos que inducen apoptosis, pero que la diferencia en su respuesta está supeditada esencialmente a la interacción con la micobacteria metabólicamente activa.

\section{Señalización intracelular asociada con la inducción de muerte durante la infección con Mycobacterium tuberculosis}

Uno de los puntos más relevantes en el entendimiento de las interacciones entre la micobacteria y el macrófago es investigar cómo este patógeno traduce señales al interior de los fagocitos mononucleares. Varios hechos hacen pensar que la infección micobacteriana es similar a la activación clásica del macrófago en respuesta a estímulos como el IFN $\gamma$, por la producción de TNFa, NO y la activación de la caspasa-1 que se observa durante la infección (52).

Hemos encontrado, por ejemplo, que la infección de macrófagos de ratón con $M$. tuberculosis y la estimulación con el PPD y el ManLAM, inducen la actividad de proteínas cinasas de tirosina (protein tyrosine kinase, PTK). Una vez en contacto con la micobacteria o sus productos, los macrófagos transfieren grupos fosfatos radiactivos a sustratos con tirosinas disponibles (53). Esta transferencia es inhibida por fármacos de amplio espectro sobre las PTK como el tirfostín AG126, o específicos de JAK2/STAT1-a, como el AG490 (53). Además, ambos fármacos inhibieron la producción de TNFa, $\mathrm{NO}$, la activación de la caspasa 1 y la apoptosis. Esta evidencia se complementó con el estudio del estado de fosforilación de la JAK2/STAT1-a y la translocación al núcleo de STAT1-a, lo cual indicó efectivamente que la infección con $M$. tuberculosis puede activar esta vía de señalización que se asocia con la inducción de muerte (53).

Aunque nuestros resultados señalaron que la muerte celular era regulada por las citocinas TNFa 
e IL-10, el bloqueo de ellas retardó la apoptosis inducida por M. tuberculosis pero no la inhibió; esto sugería que la producción de TNFa e IL-10 no podían explicar la totalidad de la muerte celular observada con la infección y motivó la búsqueda de otros moduladores de la muerte celular, como el $\mathrm{Ca}^{+2}$. Este catión divalente puede funcionar como segundo mensajero, efector y cofactor de enzimas que participan en la muerte celular. El tratamiento con el quelante BAPTA/AM, que elimina el $\mathrm{Ca}^{+2}$ intracelular y el extracelular, disminuyó la producción de $\mathrm{NO}$ y evitó el daño mitocondrial que se había observado desde las dos horas después de la infección con $M$. tuberculosis $(39,55)$.

Mientras la infección con $M$. tuberculosis indujo el influjo de $\mathrm{Ca}^{+2}$ en la célula huésped, el ManLAM impidió dicha captación (39). El tratamiento con ManLAM, la remoción del $\mathrm{Ca}^{+2}$ o el bloqueo de elementos partícipes de la homeostasis del $\mathrm{Ca}^{+2}$, como son el cAMP y la calmodulina, inhibieron la activación de la caspasa 1 sin afectar la producción de TNFa. Además, el bloqueo del cAMP-pero no de la calmodulina-inhibió la activación de la proteína unidora del elemento de respuesta a cAMP (CAMP responsive element binding protein, $\mathrm{CREB}$ ).

Finalmente, encontramos que esta vía de señalización, que designamos como vía temprana del $\mathrm{Ca}^{+2}$, afectó directamente la expresión de la proteína mitocondrial Bcl-2, la cual tienen reconocidas funciones antiapoptóticas (39).

A partir de estos estudios, propusimos que para la ejecución de la muerte celular se manifiestan eventos tanto tempranos como tardíos. Los tempranos estarían supeditados a la señalización por el calcio, la cual lleva a daño mitocondrial y activación de la caspasa 1. Los eventos tardíos son dependientes de las citocinas TNFa e IL-10 que regulan la expresión y activación de los efectores, NO y caspasas. Nuestros hallazgos, además, evidenciaban que la inducción de apoptosis en macrófagos infectados con $M$. tuberculosis es un fenómeno complejo y finamente regulado por factores tanto del húesped como del microbio.

Con estos hallazgos concebimos a la apoptosis como una respuesta innata de los fagocitos mononucleares que lleva a la eliminación del nicho favorable para la replicación micobacteriana, sin desencadenar una reacción inflamatoria. Por lo tanto, la apoptosis de los macrófagos infectados con $M$. tuberculosis podría ser considerada como un mecanismo de defensa frente a la infección. No obstante, nuestro trabajo en células de ratón tenía que ser validado en células humanas para poder justipreciar su vigencia.

\section{EI Nramp1 es irrelevante en la infección con Mycobacterium tuberculosis, emergencia del locus sst1 y del gen Ipr1.}

Mientras los estudios de nuestro grupo estaban encaminados a determinar cuál era la asociación entre los mecanismos de resistencia a la infección micobacteriana y los de muerte celular, hacia 1996, dos investigadores del Trudeau Institute de Saranac Lake, New York, publicaron varias hallazgos que demostraron en el modelo de ratón que la infección con cepas virulentas de $M$. tuberculosis, como la H37Rv, no estaba influenciada por la presencia del gen Nramp1 (57-61). Por el contrario, algunas de las cepas de ratones inicialmente definidas como resistentes a la infección con $M$. bovis BCG resultaron ser más susceptibles. No obstante los múltiples estudios hechos en humanos, nunca fue posible detectar una asociación significativa entre las variantes del Nramp1 y la susceptibilidad a tuberculosis (57-61).

A pesar del desconocimiento que había sobre los genes que gobiernan la resistencia y la susceptibilidad a la infección, algunos datos sugerían que la célula portadora del fenotipo de resistencia era un "componente de la inmunidad innata con capacidad fagocítica". Por ejemplo, en animales Scid (ratones deficientes de células T y B) originados en diferentes acervos genéticos se observa susceptibilidad diferencial a la infección con parásitos intracelulares (62). Los animales a los que selectivamente se les eliminan con sílice las células del sistema fagocítico mononuclear son más susceptibles a la infección con $M$. tuberculosis (63).

Se siguió la búsqueda en el modelo de ratón de genes que confirieran resistencia o susceptibilidad a bacterias virulentas como $M$. tuberculosis Erdman $(64,65)$. Los animales C3HeB/FeJ resultaron ser más susceptibles que los de cualquier otra cepa y los C57BL/6 eran "naturalmente resistentes". Los animales susceptibles recibieron trasplante de médula ósea de los ratones resistentes y, mediante mapeo génico, se identificó un locus mayor de susceptibilidad asociado con el control de la tuberculosis, denominado sst1 (susceptibility to tuberculosis 1) $(64,65)$.

A estos estudios les sucedió la generación de animales congénicos obtenidos a parir de cruces 
entre los C3HeB/FeJ x C57BL/6. Los congénicos fueron designados como C3H.B6-sst1 (sst ${ }^{1}{ }^{\mathrm{R}}$ ). Si bien los $s s t 1^{R}$ eran capaces de controlar la infección más eficientemente que los $s s t 1^{S}$, la diferencia era aún mayor entre los $s s t 1^{R}$ y los naturalmente resistentes C57BL/ 6 en términos de supervivencia, lo que sugirió que otros loci diferentes al transferido a los $s s t 1^{R}$ podían tener un efecto considerable en el control de la infección (66).

Una característica importante de los animales susceptibles es la presencia de lesiones granulomatosas con amplias áreas necróticas, que están ausentes en los animales resistentes, y en cuyas lesiones se observan infiltrados de mononucleares apoptóticos (66). Cuando el locus sst1 se expresaba en animales Scid se continuaba evidenciando el fenotipo de resistencia conferido por dicho locus, por lo que el gen responsable debía hacer parte de un componente de la inmunidad innata (66).

La estrategia de posicionamiento de clones llevó a la identificación de una región mínima en el locus, delimitada por los marcadores D1Mit439 y D1Mit49, que debería contener dicho gen. La región identificada era de 3.5 a $6 \mathrm{Mb}$, aproximadamente, y abarcaba 22 genes conocidos (66). Se decidió utilizar la estrategia del RT-PCR RACE (reverse transcriptase-mediated polymerase chain reaction and rapid amplification of complementary DNA ends) para identificar un gen que se expresara exclusivamente en los animales resistentes durante la infección (66). Uno de los productos que consistentemente se expresó fue el gen Ifi75, denominado Ipr1 (intracelullar pathogen resistance 1) ya que confería resistencia, por lo menos, a dos patógenos intracelulares: $M$. tuberculosis y Listeria monocytogenes $(67,68)$.

La secuencia del gen predice un producto que contiene dominios del tipo Sp100 en la región $\mathrm{N}$-terminal, un motivo de receptor nuclear LXXLL, una señal bipartita de localización nuclear y un dominio denominado como SAND en el extremo C-terminal. Utilizando sondas específicas para los dominios Sp100 y SAND del gen Ipr1 en ensayos de Northern Blot, fue posible establecer que la expresión del gen Ipr1 es detectable exclusivamente en los pulmones de animales resistentes, específicamente en los macrófagos, dos semanas después de iniciarse la infección (66-68).

Se generaron animales $\mathrm{C} 3 \mathrm{HeB} / \mathrm{FeJ}$ transgénicos con el cDNA que codifica para el Ipr1. Para asegurar una expresión específica de macrófagos, el gen se ensambló con el promotor del receptor scavenger humano tipo A; sin embargo, no se tuvo en cuenta que este receptor es regulado negativamente durante la infección micobacteriana y, en general, en las respuestas inflamatorias (66-68). Este promotor fue menos eficiente que el nativo; no obstante, a plazos cortos y con L. monocytogenes, fue posible establecer la contribución del gen Ipr1 (66).

Estudios posteriores demostraron que el gen más homólogo al Ipr1 en los humanos, el SP110, tiene tres variantes polimórficas que correlacionan con susceptibilidad a la tuberculosis en el occidente (69) y sur de África (70). A pesar de estas asociaciones, los genes responsables de susceptibilidad 0 resistencia a la tuberculosis en los humanos siguen siendo objeto de discrepancias $(71,72)$.

Independiente de la contribución genética asociada con susceptibilidad o resistencia a la infección micobacteriana, parece que el fenotipo de muerte celular se conserva. Los macrófagos que portan alelos de resistencia (como el Nramp1 y el Ipr1) sufren apoptosis en respuesta a la infección, mientras que en los macrófagos primarios deficientes del Ipr1, se observa necrosis (66). En nuestro grupo, este fenotipo lo hemos hecho evidente cuando comparamos los monocitos de pacientes con tuberculosis con los monocitos de controles sanos.

\section{La muerte celular en monocitos y macrófagos humanos en respuesta a la infección}

Como se ha mencionado, una de las consecuencias de la interacción entre la micobacteria y el macrófago es la inducción de la muerte de las células húesped $(39,44,47-53,55,73-93)$. De los dos patrones de muerte celular, la apoptosis se ha asociado con el control de M. tuberculosis, debido a que los cuerpos apoptóticos que contienen el bacilo pueden ser reconocidos y fagocitados por macrófagos y células dendríticas reclutadas al sitio de la infección, lo que permitiría mayor control de la micobacteria $(78,94)$. Por el contrario, la necrosis se ha asociado con diseminación de la bacteria y daño tisular $(66,95)$. Sin embargo, algunos autores han sugerido que las células apoptóticas pueden ser fagocitadas por células con menor capacidad efectora, como monocitos inmaduros recién reclutados al granuloma, lo que resultaría en una diseminación más que en un control de la infección $(96,97)$. 
Algunos estudios de nuestro grupo han demostrado que la apoptosis de las células infectadas se podría correlacionar con el control de la infección micobacteriana $(47-49,51)$. Se ha observado que los macrófagos de ratón que expresan genes relacionados con la resistencia a la tuberculosis y a otras infecciones intracelulares están más encaminados a sufrir apoptosis en respuesta a la infección que las células que provienen de acervos susceptibles, en los cuales se ha evidenciado que los macrófagos sufren necrosis (66). Igualmente, en cultivos de monocitos aislados de sangre periférica de pacientes con tuberculosis, la infección con $M$. tuberculosis o el tratamiento con PPD induce a una proporción de ellos a sufrir apoptosis y otra a sufrir necrosis; en contraste, cuando se infectan monocitos de individuos sanos se observa que éstos únicamente sufren apoptosis (47-49).

Algunas evidencias sugieren que las diferencias existentes en los estadios de diferenciación de los monocitos hacia macrófagos, se podrían correlacionar con la capacidad de activar mecanismos que controlen la infección. En el granuloma, que es la lesión que se forma in vivo en el sitio de infección, parece haber un reclutamiento de células que detentan diferentes grados de diferenciación. La localización de los fagocitos mononucleares inmaduros CD14+, en los cuales se ha descrito alta expresión del receptor scavenger tipo $\mathrm{A}\left(\mathrm{SRA}^{+}\right)$y baja de las moléculas del complejo mayor de histocompatibilidad clase II (MHC II), se da, principalmente, en el centro del granuloma. Estas células se asociaron con un mayor número de bacterias. Las células más maduras, con mayores niveles de MHC II, baja expresión del SRA y de CD14, se localizaron periféricamente en el granuloma y tenían menor número de bacterias (98). Aunque el significado exacto de esta distribución no se ha entendido del todo, es evidente que las diferencias en la maduración y la carga de bacterias se asocian con la arquitectura del granuloma (98).

Si bien algunos estudios sugieren que la maduración y diferenciación de las células fagocíticas podría afectar los mecanismos de muerte en los macrófagos y la capacidad de controlar las micobacterias $(47,74,76-78,99)$, los estudios no son claros sobre la forma como la muerte celular de monocitos y macrófagos afecta la capacidad de controlar el crecimiento micobacteriano. En este sentido, y con la intención de buscar nuevas estrategias que sirvan para intervenir el crecimiento micobacteriano y la muerte celular, durante los últimos años en el Grupo de Inmunología Celular e Inmunogenética se han empezado a caracterizar las diferencias entre los monocitos de controles sanos y de pacientes con tuberculosis, antes del tratamiento, a los tres y a los seis meses del mismo (49). Se ha analizado la expresión de diferentes marcadores funcionales que pudiesen dar cuenta en alguna medida de las alteraciones en la madurez de los monocitos (49).

En los pacientes con diferentes formas clínicas de tuberculosis y en controles sanos se estudió la expresión de superficie de CD206, TLR-2, IFN$\gamma$ R1, CD40, HLA-DR, CD36 y CD163 en monocitos $\mathrm{CD} 14^{+}$. En general, se observó que en los monocitos de los pacientes había un alto porcentaje de células $\mathrm{CD}^{+} 4^{+}$y una menor proporción de monocitos $\mathrm{CD}_{14}{ }^{+} \mathrm{CD} 36^{+}$y CD14 ${ }^{+} \mathrm{HLA}-\mathrm{DR}{ }^{+}$, en contraste con los monocitos de los controles sanos, lo cual sugiere que las poblaciones de los pacientes deben ser diferentes (49).

Además de la expresión de estos marcadores, también se estudió la inducción de necrosis y apoptosis en respuesta a $M$. tuberculosis. Como se había descrito anteriormente (48), en la respuesta a la infección micobacteriana, en los monocitos de los controles sanos se observó inducción de apoptosis y en los de los pacientes, una fracción de ellos sufrió necrosis y otra apoptosis. A los tres y a los seis meses del tratamiento antituberculoso se observó una reversión de las poblaciones en circulación. Tanto los monocitos CD14 ${ }^{+} \mathrm{CD} 36^{+}$, como los CD14 ${ }^{+} \mathrm{HLA}^{-D R^{+}}$y los pronos a la necrosis revirtieron su fenotipo y se comportaron como los de sujetos sanos (49). La restauración de las alteraciones observadas con la terapia en los monocitos, sugiere que son efecto de la enfermedad activa y no intrínseca a los pacientes.

La inducción de muerte celular de los monocitos humanos en respuesta a la infección con $M$. tuberculosis también es modulada por citocinas como el TNFa y la IL-10 $(47,48)$. Sin embargo, los estudios funcionales de los posibles mecanismos involucrados en dicha muerte se han dificultado debido a las limitaciones en el número de células, lo que nos ha impelido a desarrollar un modelo a partir de la línea celular promonocítica humana U937. Cuando estas células se tratan con ésteres de forbol, como el PMA, dejan de dividirse, se diferencian hacia monocitos $y$, posteriormente, a macrófagos. Al tener células promonocíticas y macrófagos es posible hacer estudios para 
establecer los efectos en apoptosis y necrosis con el control micobacteriano, en concierto con el estado de diferenciación.

Los hallazgos obtenidos indican que cuando los promonocitos U937 se comparan con los macrófagos derivados de esta misma línea, las células más diferenciadas tienen mayor capacidad de controlar la replicación micobacteriana, en una forma dependiente del tiempo y de la multiplicidad de infección. Los resultados indican que la diferenciación podría afectar la producción de TNFa e IL-10 en respuesta a la infección micobacteriana. Mientras la cantidad de macrófagos productores de TNFa es mayor que la de promonocitos, la proporción de promonocitos que producen IL-10 es mayor que la de las células más diferenciadas.

Previamente hemos mencionado que estas citocinas juegan papeles opuestos en la muerte celular, en la activación del macrófago y en el control del crecimiento intracelular de la micobacteria $(47,48,52)$. Estas observaciones han sido validadas utilizando la línea celular U937. El bloqueo del TNFa impide la inducción de apoptosis en los macrófagos, mientras que el bloqueo de la IL-10 en los promonocitos previene la inducción de necrosis; el bloqueo de ambas citocinas afecta la capacidad de controlar intracelularmente a $M$. tuberculosis.

El antagonismo entre el TNFa y la IL-10 en la modulación de la muerte celular condujo a explorar posibles blancos farmacológicos capaces de inhibir o modular la necrosis y la apoptosis, a fin de establecer más claramente su efecto sobre el crecimiento intracelular de $M$. tuberculosis (47).

Con base en el análisis de los fenómenos que modulan la muerte celular en los macrófagos de ratón y en los monocitos humanos, se propuso que deben coexistir, al menos, dos hechos detonantes de la muerte celular: la IL-10 como señal antiapoptótica y la presencia de una señal deletérea, como el $\mathrm{Ca}^{+2}$, involucrado tanto en la modulación de la apoptosis como de la necrosis. Se consideró que uno de los blancos celulares modulado por el calcio, e involucrado tanto en la apoptosis como en la necrosis, lo podrían constituir algunas isoformas de la fosfolipasa A2 (PLA-2) dependientes del $\mathrm{Ca}^{+2}$ (100-103). En estudios previos se le había asociado fuertemente con actividades anti-micobactericidas (104). Se han descrito isoformas extracelulares de la PLA-2 en fluidos pleurales de pacientes con tuberculosis (105). El bloqueo de la cPLA-2 tipo IV durante la infección in vitro con M. avium, inhibió la apoptosis de macrófagos humanos, mientras que el suministro exógeno del ácido araquidónico disminuyó la viabilidad de la bacteria (106).

Por el contrario, el bloqueo in vitro de la PLA-2 con quinacrina y araquidonil-trifluorometilcetona (inhibidor de la cPLA-2 tipo IV), se correlaciona con un aumento en el crecimiento intracelular de la micobacteria (107). En el sistema descrito, el bloqueo de la PLA-2 con el ácido 7,7-dimetileicosadienoico (DEDA), previene la inducción de necrosis tanto en las líneas celulares como en células de pacientes y aumenta la proporción de células productoras de TNFa, disminuye la proporción de células productoras de IL-10 y reduce el crecimiento intracelular de M. tuberculosis (47).

Aunque nuestros resultados señalan que la PLA-2 está involucrada en la modulación de la muerte celular, parece que la misma enzima juega papeles diferentes según el estado de diferenciación de los fagocitos mononucleares. Además, nuestros hallazgos no aclaran cuál o cuáles de los metabolitos derivados de la actividad de la PLA-2 podría ser el modulador directo de la muerte y tampoco dejan en claro si éste es responsable de los efectos sobre la producción de citocinas y mucho menos cómo afectarían el crecimiento intracelular de M. tuberculosis. La identificación de este metabolito celular, así como la evaluación de su posible papel en la función del macrófago y del control del crecimiento micobacteriano, se ha convertido en uno de los interrogantes esenciales que estamos investigando a corto plazo con el fin de tener a mano herramientas que nos permitan un mejor entendimiento del papel de la muerte celular en la patogénesis de la enfermedad.

\section{Subpoblaciones de monocitos y tuberculosis}

Las alteraciones encontradas en los monocitos de los pacientes con tuberculosis, evidenciadas en la expresión de CD14, CD36 y HLA-DR, así como la necrosis en respuesta a la infección e incremento de los conteos de monocitos CD14+ ${ }^{+}(49)$, nos sugirió que dichas alteraciones podrían explicarse por diferencias en la distribución de subpoblaciones o en el estado de madurez de los monocitos. Éste es uno de los tópicos en los que actualmente estamos trabajando.

En humanos, las subpoblaciones de monocitos de sangre periférica se definieron hace más de 20 años de acuerdo con la expresión de las moléculas de superficie CD14 y CD16 (108). El CD16 es un receptor de baja afinidad para la porción Fc de los 
anticuerpos lgG, el cual media la fagocitosis de complejos inmunes (antígeno-anticuerpo). EI CD14, junto con el TLR-4 y el MD-2, es responsable del reconocimiento del lipolisacáridos presente en las bacterias Gram negativas, al inducir la señalización y la activación de respuestas proinflamatorias en los fagocitos mononucleares. La primera descripción de estas células se hizo en 1988, y definió dos tipos principales de monocitos, unos con alta densidad de expresión de CD14 y que no expresan CD16 $\left(\mathrm{CD} 14^{++} \mathrm{CD} 16\right)$ y otros con baja expresión de CD14 y que expresan CD16 (CD14+CD16 $)(108)$ (figura 4).

Los monocitos $\mathrm{CD} 14^{++} \mathrm{CD} 16$ son más grandes, tienen $18,4 \pm 1,7 \mu \mathrm{m}$ de diámetro y se les llaman "clásicos" o "convencionales" porque representan entre el $80 \%$ y el $90 \%$ de los monocitos circulantes (109-111). Se caracterizan por expresar mayores niveles de CD36, CD64, CD33, CCR1, CCR2, CD62L (112-114). Los monocitos CD14 ${ }^{+} \mathrm{CD} 16^{+}$con $14 \pm 3,8 \mu \mathrm{m}$ de diámetro, constituyen del $10 \%$ al $20 \%$ de los monocitos en circulación (111) y, son llamados "proinflamatorios" porque producen más TNFa por célula pero no expresan IL-10 en comparación con los monocitos clásicos (115); además, porque su población se expande en numerosas condiciones como trastornos autoinmunes (116), sida (117), cáncer (118), sepsis (119), etc. Se caracterizan por expresar HLA-DR, CD86, CCR5 y CX3CR1 (112-114).

Más recientemente, se ha definido que los monocitos $\mathrm{CD}_{16}{ }^{+}$se pueden dividir en dos grupos, unos con baja expresión de CD14 (CD14+CD16+) y otros con alta expresión de esta molécula $\left(\mathrm{CD} 14^{++} \mathrm{CD} 16^{+}\right)$ $(120,121)$. Los monocitos $\mathrm{CD} 14^{++} \mathrm{CD} 16^{+}$se han encontrado aumentados en algunos casos junto con los CD14 ${ }^{+} \mathrm{CD} 16^{+}$, como en el curso de sepsis (114) y, en otros casos, se encuentran como única subpoblación aumentada, como en el asma (122). Se caracterizan por expresar simultáneamente CCR1, CCR2, CXCR2, CCR5 y CX3CR1. Además, este subgrupo expresa más CD86, CD54 and HLADR y menos CD64 comparado con la subpoblación CD14 ${ }^{++}$CD16- (112-114).

Ha habido otros enfoques para subdividir las subpoboblaciones de monocitos con base en

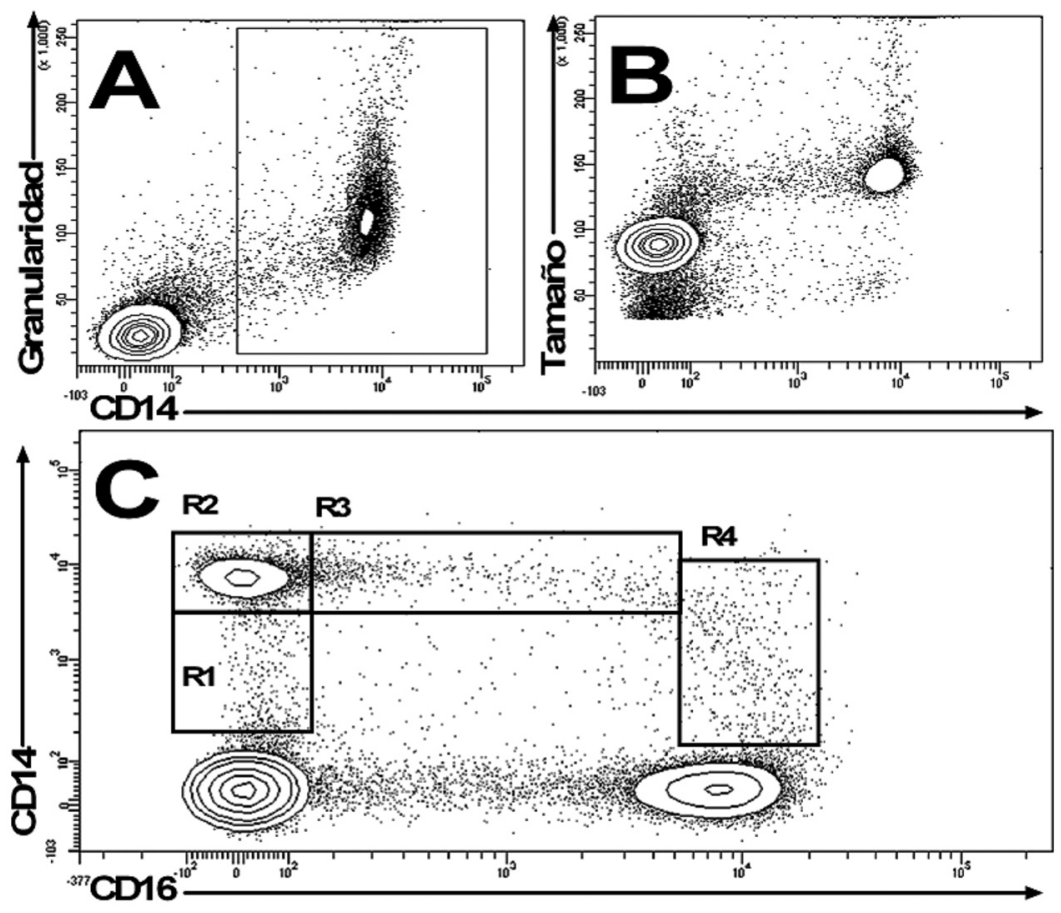

Figura 4. Subpoblaciones de monocitos basada en la distribución de CD14 y CD16. La inmunotipificación con CD14 y CD16 muestra los monocitos clásicos CD14 ${ }^{++}$CD16- (R2), los CD14 ${ }^{+}$CD16- (R1), los CD14 ${ }^{++}$CD16 $6^{+}$(R3) y los CD14 ${ }^{+}$CD16 $6^{+}$. No obstante, desde el punto de vista funcional tienden a considerarse como dos subpoblaciones, unos con alta densidad de expresión de CD14 y que no expresan CD16, (CD14++CD16) y, otros con baja expresión de CD14 y que expresan CD16 (CD14 CD16 $\left.{ }^{+}\right)$. A) y B). Se observan los cambios en la granularidad y el tamaño de los monocitos, respectivamente. C) Inmunotipificación con anti-CD14 y anti-CD16. 
la expresión de otros receptores Fc, receptores scavenger, receptores de quimiocinas y la expresión de moléculas de adhesión. En el primer caso, el CD64, que es una glucoproteína de membrana que funciona como receptor de alta afinidad de la lgG (123), se ha observado que las células CD64

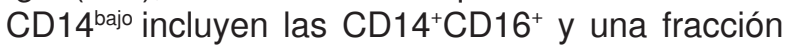
de las CD14 $^{++}$CD16 $(120)$. El receptor scavenger del grupo B, el CD163, se ha reportado ausente en los monocitos $\mathrm{CD} 14^{+} \mathrm{CD} 16^{+}$y presente en los CD14 ${ }^{++}$CD16 (124). En términos de expresión de quimiocinas y selectinas, el CCR2, receptor del MCP-1, y el CD62L están aumentados en las células $\mathrm{CD} 14^{++} \mathrm{CD} 16$, mientras que en las células $\mathrm{CD}_{14}{ }^{+} \mathrm{CD} 16^{+}$hay mayor expresión del CX3CR1 y del CCR5 $(113,125)$. Por lo tanto, se ha considerado que el uso del CD16 para la definición de subpoblaciones de monocitos de sangre, ofrece la mejor discriminación de éstas y es la forma más utilizada y aceptada actualmente para el estudio de los monocitos.

La mayoría de los estudios que se han hecho en subpoblaciones de monocitos comparan esencialmente monocitos $\mathrm{CD} 14^{+} \mathrm{CD} 16^{+}$y $\mathrm{CD} 14^{+} \mathrm{CD} 16$. A pesar de que a estas células se le han demostrado fenotipos y funciones distintas, en varios casos los resultados son contradictorios ya que se no se consideran mucho las variaciones en la expresión del CD14, lo que dificulta el entendimiento de las implicaciones fisiológicas de estas subpoblaciones.

En el 2003, se describieron dos subpoblaciones de monocitos en la sangre de ratones, de acuerdo con la expresión diferencial de Ly6C, CCR2 y CX3CR1 (126). Se encontró que el subgrupo $\mathrm{Ly}_{6 \mathrm{C}}{ }^{+} \mathrm{CCR} 2^{+}$migraba rápidamente a los tejidos peritoneales inflamados de una forma dependiente de la expresión de CCR2 y, por lo tanto, recibió el nombre de monocitos "inflamatorios", mientras que los $\mathrm{Ly} 6 \mathrm{C}-\mathrm{CX} 3 \mathrm{CR} 1^{+}$se consideraron precursores de los fagocitos residentes de bazo, pulmón, etc., y los denominaron monocitos "precursores de macrófagos residentes".

Infortunadamente, estos hallazgos y la terminología empleada han generado gran confusión. Teniendo en cuenta el perfil de expresión de quimiocinas, los monocitos inflamatorios del ratón corresponden a los clásicos del humano, mientras que los residentes de ratón corresponden a los proinflamatorios del humano. Sin embargo, a pesar de ser homólogos en la expresión de quimiocinas, sus funciones son completamente opuestas. De esta forma, la dicotomía y la verdadera correlación en el fenotipo y la función de estas subpoblaciones entre los monocitos humanos y del ratón permanecen sin esclarecer.

Desde el punto de vista funcional en un modelo de quimiotaxis transendotelial de los monocitos, los datos revelaron que las células $\mathrm{CD} 14^{+} \mathrm{CD} 16^{+}$ eran menos sensibles a MCP-1 que la población predominante de células $\mathrm{CD}_{1} 4^{++} \mathrm{CD} 16-$, lo que demuestra su potencial para la migración diferencial (125). La estimulación de células con MCP-1 y, en menor proporción con MIP-1a, regula positivamente la expresión de la integrina $\beta 2$ (CD11b/CD18) en los monocitos CD14 ${ }^{++}$CD16- (125). Estos hallazgos han llevado a proponer que mientras el tratamiento con MCP-1 en las CD14+CD16+ regula su potencial migratorio hacia los sitios de inflamación, en las células $\mathrm{CD}_{14}{ }^{++} \mathrm{CD} 16$ esta quimiocina favorece la capacidad de adherencia (56). Consideramos que estas observaciones sugieren el efecto que los microambientes pueden tener en la iniciación o preactivación de los fagocitos antes de que entren en contacto con los microorganismos, lo que afecta la posterior eficiencia de la respuesta funcional.

Si bien está muy definido que los monocitos CD16 ${ }^{+}$ se incrementan en una variedad de entidades inflamatorias, como la enfermedad de Crohn (116), la artritis reumatoide (127) y la aterosclerosis (128), entre otras; su perfil de producción de citocinas no es tan claro. Se ha encontrado -con la tinción intracelular o la detección del TNFa en sobrenadantes de cultivo- que los monocitos $\mathrm{CD}_{16}{ }^{+}$presentan mayores niveles que los CD16 en respuesta al lipolopisacárido $(114,115)$. Sin embargo, la evaluación de la actividad biológica y de los niveles del ARN mensajero de TNFa, IL$1 \beta$ e IL-10 demostró menor producción de estas citocinas en los monocitos CD16+ que en los CD16en respuesta al mismo estímulo (129).

El hallazgo que es consistente entre los diferentes estudios es la baja producción de IL-10 y mayor de IL-12 por parte de las células CD $14^{+} \mathrm{CD} 16^{+}$. Además, se ha demostrado mayor producción de IL-10 por parte de los monocitos $\mathrm{CD}_{14}{ }^{++} \mathrm{CD} 16^{+}$ en respuesta al lipolopisacárido y al zimosán en comparación con las otras subpoblaciones (114). Estas diferencias podrían explicarse por la aproximación experimental usada tanto para el enriquecimiento de los subpoblaciones, como en el método para evaluar su producción. Puede ser que la interpretación de los resultados se dificulte por la evaluación de dos subpoblaciones en lugar de tres y, además, la producción de estas citocinas 
definitivamente debe depender de la activación clásica o alternativa que reciban estas células, pero esto aún no se ha establecido.

Inicialmente se encontró que los monocitos CD16 ${ }^{+}$ se caracterizaban por un tamaño considerablemente menor, múltiples gránulos citoplasmáticos, menor adherencia y menor capacidad de fagocitosis (111), lo que hizo pensar que correspondían a una población de monocitos menos madura. Sin embargo, se ha demostrado una alta la expresión del HLA-DR (120) y de CD43 en estos monocitos y una baja de CD13 y CD33 (130). Además, se ha observado que en cultivo, el fenotipo de los monocitos $\mathrm{CD} 14^{++} \mathrm{CD} 16$ cambia a CD14 ${ }^{+} \mathrm{CD} 16^{+}$en respuesta a tratamientos como M-CSF, LPS, TNFa $(131,132)$, lo que ha llevado a sugerir que las células CD16 ${ }^{+}$corresponden a un estadio de diferenciación mayor que los CD16 y que semejan en el fenotipo de membrana a los macrófagos tisulares, especialmente a los de macrófagos alveolares. Sin embargo, llama la atención que los fagocitos CD16 ${ }^{+}$ tengan mayores señales apoptóticas (anexina $\mathrm{V}^{+}$) luego del cultivo in vitro (133) y que expresen basalmente más genes proapoptóticos que las CD16- (134), lo que sugeriría que, posiblemente, estas células requieren condiciones especiales de cultivo, como la utilización de M-CSF, que las rescate de la muerte; esto se asocia con el hecho de que las células CD16+expresan más receptores para M-CSF que las CD16- (135). La menor resistencia a la muerte in vitro es indicativa de que estas células son menos maduras que las CD16.

Además, se había definido que los monocitos $\mathrm{CD}_{16}{ }^{+}$tenían una baja capacidad fagocítica de eritrocitos con opsonización con anticuerpos (111), posiblemente porque los monocitos CD16- tienen mayor expresión del receptor de alta afinidad para inmunoglobulinas, el CD64. Por el contrario, los estudios posteriores reportaron una mayor capacidad fagocítica de partículas con opsonización por parte de los monocitos CD16 ${ }^{+}(136-138)$ y se ha encontrado en estas células, mayor expresión del receptor para la fracción C3 del complemento y de proteínas asociadas con la fagocitosis por receptores Fc, como Lyn, Hck, Arpc5, entre otras (130). Asimismo, se ha demostrado que los monocitos $\mathrm{CD}^{+} 6^{+}$tienen alta actividad de células presentadoras de antígenos provenientes del citomegalovirus, la PPD y virus de la influenza, lo que permite una mayor activación de los linfocitos T que los monocitos CD16- $(124,139)$. Esto se ha asociado con la mayor expresión de moléculas de histocompatibilidad clase II y de moléculas coestimuladoras por los monocitos CD16 ${ }^{+}$.

Se ha descrito, también, que los monocitos CD16+, los cuales expresan más gangliósido GM1, tienen mayor capacidad endocítica de moléculas, como el dextrán, y mayor actividad fagocítica sobre M. bovis BCG que los monocitos CD16 (140). Además, se ha observado que los monocitos $\mathrm{CD}_{16}{ }^{+}$preferencialmente se diferencian a células dendríticas, mientras que los CD16-, lo hacen a macrófagos $(7,141,142)$. Por el contrario, se ha definido que los monocitos CD16 son más eficientes en la remoción de células apoptóticas y tiene mayor expresión de genes que codifican proteínas con actividad microbicida, como la lisozima, la proteína catiónica de los eosinófilos, la catepsina $\mathrm{G}$ y la mieloperoxidasa, entre otros $(134,135)$.

En cuanto a la infección micobacteriana, no existen muchos estudios de la frecuencia y la función de estas subpoblaciones. Hay un reporte que indica un aumento en la expresión de CD16 en los monocitos de pacientes con tuberculosis (143); sin embargo, otro grupo de investigación demostró que no hay cambios en las proporciones de monocitos $\mathrm{CD}_{14}{ }^{++} \mathrm{CD} 16-$ y $\mathrm{CD}^{-} 4^{+} \mathrm{CD} 16^{+}$antes ni después del tratamiento antituberculoso (144). Resultados de nuestro grupo -que no se han publicadodemuestran que los pacientes con tuberculosis tienen aumentada la frecuencia y el número absoluto de la subpoblación de los monocitos $\mathrm{CD} 14^{++} \mathrm{CD} 16^{+}$. Además, estamos evaluando algunas respuestas funcionales de los monocitos $\mathrm{CD}^{+}{ }^{+}$luego de infección micobacteriana, lo que nos ha llevado a proponer que los monocitos $\mathrm{CD}_{16}{ }^{+}$, posiblemente, estén fagocitando más micobacterias, pero debido a su susceptibilidad intrínseca, mueren rápidamente luego de la infección y, por lo tanto, no alcanzan a producir niveles importantes de las citocinas proinflamatorias. Debido a que las células $\mathrm{CD}_{16}{ }^{+}$no son buenas eliminando las células apoptóticas, éstas deben sufrir necrosis que lleva a la liberación de la micobacteria, lo que sugeriría que los monocitos CD16- tienen mejor capacidad de respuesta frente a la infección micobacteriana que los monocitos CD16 ${ }^{+}$.

\section{Conclusiones}

Es claro que los monocitos de los pacientes con tuberculosis tienen características funcionales y fenotípicas que contrastan con los controles sanos. Estas diferencias parecen estar explicadas en parte por el aumento en las células CD16 ${ }^{+}$, que son menos maduras y más susceptibles a la 
muerte celular. El aumento de esta subpoblación posiblemente sea un efecto sistémico de la infección, aunque las implicaciones o consecuencias que puedan tener los monocitos $\mathrm{CD}_{16}{ }^{+}$en el decurso de la infección son aún inciertas. Debido a que las diferencias funcionales entre los monocitos CD16 ${ }^{+}$ y CD16- no son muy claras y que no se pueden homologar con los resultados obtenidos de los modelos intervenidos de los ratones, es muy difícil por el momento dimensionar el papel de estas células en la fisiopatología de la tuberculosis. Queda aún mucho terreno por explorar en cuanto a la interacción de $M$. tuberculosis con cada una de estas subpoblaciones para entender cómo es su capacidad fagocítica, la maduración de los fagosomas que contienen la micobacteria y su capacidad microbicida, entre otras.

Además, el entendimiento de los mecanismos que gobiernan la muerte celular de los fagocitos mononucleares infectados, como es, al parecer, el estado de maduración y diferenciación de estas células, nos abrirá posibilidades en la comprensión de la patogénesis de la enfermedad, de los mecanismos innatos de resistencia y de desarrollo de la inmunidad adaptativa. Asimismo, debido a los diferentes componentes que favorecen la diferenciación y la maduración de los fagocitos mononucleares, se podría pensar en la implementación de estudios que evalúen algún tipo de intervención farmacológica.

\section{Conflicto de intereses}

Los autores declaran que no existen conflictos de interés. Esta revisión está enmarcada dentro del desarrollo de trabajo doctoral de Diana Castaño quien ha sido beneficiaria de una beca del Programa de Doctorados Nacionales de Colciencias y cuyo trabajo también ha sido financiado por dicha institución con el Proyecto Código 111540520270 y con el Convenio para la Unión Temporal Contrato RC 431-2004.

\section{Referencias}

1. Gordon S. Alternative activation of macrophages. Nat Rev Immunol. 2003;3:23-35.

2. Gordon S, Taylor PR. Monocyte and macrophage heterogeneity. Nat Rev Immunol. 2005;5:953-64.

3. Kaufmann SH. Elie Metchnikoff's and Paul Ehrlich's impact on infection biology. Microbes Infect. 2008;10:1417-9.

4. Keitel W. The pathologists: Aschoff, Klinge and Graff. Z Rheumatol. 2008;67:165-71.

5. van FR, Cohn ZA, Hirsch JG, Humphrey JH, Spector WG, Langevoort HL. The mononuclear phagocyte system: a new classification of macrophages, monocytes, and their precursor cells. Bull World Health Organ. 1972;46:84552.

6. Hume DA, Ross IL, Himes SR, Sasmono RT, Wells CA, Ravasi T. The mononuclear phagocyte system revisited. J Leukoc Biol. 2002;72:621-7.

7. Yona S, Jung S. Monocytes: subsets, origins, fates and functions. Curr Opin Hematol. 2010;17:53-9.

8. Stout RD, Suttles J. Functional plasticity of macrophages: reversible adaptation to changing microenvironments. J Leukoc Biol. 2004;76:509-13.

9. Calvo KR, Sykes DB, Pasillas MP, Kamps MP. Nup98HoxA9 immortalizes myeloid progenitors, enforces expression of Hoxa9, Hoxa7 and Meis1, and alters cytokinespecific responses in a manner similar to that induced by retroviral co-expression of Hoxa9 and Meis1. Oncogene. 2002;21:4247-56.

10. Rutherford MS, Witsell A, Schook LB. Mechanisms generating functionally heterogeneous macrophages: chaos revisited. J Leukoc Biol. 1993;53:602-18.

11. Hymery N, Leon K, Carpentier FG, Jung JL, ParentMassin D. T-2 toxin inhibits the differentiation of human monocytes into dendritic cells and macrophages. Toxicol In Vitro. 2009;23:509-19.

12. Yamaoka T, Tabata Y, Ikada Y. Distribution and tissue uptake of (polyethylene glycol) with different molecular weights after intravenous administration to mice. J Pharm Sci. 1994; 83:601-6.

13. Ackland GL, Gutierrez Del AA, Yao ST, Stephens RC, Dyson A, Klein NJ, et al. Low-molecular-weight polyethylene glycol improves survival in experimental sepsis. Crit Care Med. 2010;38:629-36.

14. Chung AS, Kao WJ. Fibroblasts regulate monocyte response to ECM-derived matrix: the effects on monocyte adhesion and the production of inflammatory, matrix remodeling, and growth factor proteins. J Biomed Mater Res A.2009; 89:841-53.

15. Monner DA, Denker B. Characterization of clonally derived, spontaneously transformed bone marrow macrophage cell lines from lipopolysaccharide hyporesponsive LPS(d) and normal LPS(n) mice. J Leukoc Biol. 1997;61:469-80.

16. Wijffels JF, de RZ, Kraal G, Beelen RH. Establishment of bone marrow-derived macrophage cell lines by soft-agar cloning: regulation of macrophage heterogeneity at bone marrow level. Exp Hematol. 1993;21:538-44.

17. Seta N, Kuwana M. Human circulating monocytes as multipotential progenitors. Keio J Med. 2007;56:41-7.

18. Smith I. Mycobacterium tuberculosis pathogenesis and molecular determinants of virulence. Clin Microbiol Rev. 2003;16:463-96.

19. Raja A. Immunology of tuberculosis. Indian J Med Res. 2004;120:213-32

20. Chroneos ZC, Midde K, Sever-Chroneos Z, Jagannath C. Pulmonary surfactant and tuberculosis. Tuberculosis (Edinb ). 2009;89(Suppl.1):S10-4.

21. Korbel DS, Schneider BE, Schaible UE. Innate immunity in tuberculosis: myths and truth. Microbes Infect. 2008;10:995-1004. 
22. Koul A, Herget T, Klebl B, Ullrich A. Interplay between mycobacteria and host signalling pathways. Nat Rev Microbiol. 2004;2:189-202.

23. Blander JM, Medzhitov R. On regulation of phagosome maturation and antigen presentation. Nat Immunol. 2006;7:1029-35.

24. Colangeli R, Haq A, Arcus VL, Summers E, Magliozzo RS, McBride A, et al. The multifunctional histone-like protein Lsr2 protects mycobacteria against reactive oxygen intermediates. Proc Natl Acad Sci USA. 2009;106:4414-8.

25. Lee WL, Gold B, Darby C, Brot N, Jiang X, de Carvalho LP, et al. Mycobacterium tuberculosis expresses methionine sulphoxide reductases $A$ and $B$ that protect from killing by nitrite and hypochlorite. Mol Microbiol. 2009;71:583-93.

26. Purdy GE, Russell DG. Lysosomal ubiquitin and the demise of Mycobacterium tuberculosis. Cell Microbiol. 2007; 9:2768-74.

27. Armstrong JA, Hart PD. Response of cultured macrophages to Mycobacterium tuberculosis, with observations on fusion of Iysosomes with phagosomes. J Exp Med. 1971;134: 713-40.

28. Crowle AJ, DahI R, Ross E, May MH. Evidence that vesicles containing living, virulent Mycobacterium tuberculosis or Mycobacterium avium in cultured human macrophages are not acidic. Infect Immun. 1991;59:1823-31.

29. Hart PD, Armstrong JA, Brown CA, Draper P. Ultrastructural study of the behavior of macrophages toward parasitic mycobacteria. Infect Immun. 1972;5:803-7.

30. Clemens DL, Horwitz MA. Characterization of the Mycobacterium tuberculosis phagosome and evidence that phagosomal maturation is inhibited. J Exp Med. 1995;181:257-70.

31. Clemens DL, Horwitz MA. The Mycobacterium tuberculosis phagosome interacts with early endosomes and is accessible to exogenously administered transferrin. J Exp Med. 1996;184:1349-55.

32. de Chastellier C, Thilo L. Phagosome maturation and fusion with lysosomes in relation to surface property and size of the phagocytic particle. Eur J Cell Biol. 1997;74:49-62.

33. de Chastellier C, Thilo L. Cholesterol depletion in Mycobacterium avium-infected macrophages overcomes the block in phagosome maturation and leads to the reversible sequestration of viable mycobacteria in phagolysosomederived autophagic vacuoles. Cell Microbiol. 2006;8:242-56.

34. Gillooly DJ, Simonsen A, Stenmark H. Phosphoinositides and phagocytosis. J Cell Biol. 2001;155:15-7.

35. Hsing M, Bellenson JL, Shankey C, Cherkasov A. Modeling of cell signaling pathways in macrophages by semantic networks. BMC Bioinformatics. 2004;5:156.

36. Mendez-Samperio P, Perez A, Trejo A. Sphingosine kinase, phosphatidylinositol 3-kinase, Akt, NF-kappaB, and p300 are required for CCL5 production in Mycobacterium bovis Bacillus Calmette-Guerin (BCG)-infected epithelial cells. Cell Immunol. 2007;249:94-100.

37. Vergne I, Chua J, Deretic V. Tuberculosis toxin blocking phagosome maturation inhibits a novel $\mathrm{Ca2}+$ /calmodulinPI3K hVPS34 cascade. J Exp Med. 2003;198:653-9.
38. Yadav M, Clark L, Schorey JS. Macrophage's proinflammatory response to a mycobacterial infection is dependent on sphingosine kinase-mediated activation of phosphatidylinositol phospholipase $\mathrm{C}$, protein kinase $\mathrm{C}$, ERK1/2, and phosphatidylinositol 3-kinase. J Immunol. 2006;176:5494-503.

39. Rojas M, Garcia LF, Nigou J, Puzo G, Olivier M. Mannosylated lipoarabinomannan antagonizes Mycobacterium tuberculosis-induced macrophage apoptosis by altering $\mathrm{Ca}+2-$ dependent cell signaling. J Infect Dis. 2000;182:240-51.

40. Chua J, Vergne I, Master S, Deretic V. A tale of two lipids: Mycobacterium tuberculosis phagosome maturation arrest. Curr Opin Microbiol. 2004;7:71-7.

41. Deretic V, Singh S, Master S, Harris J, Roberts E, Kyei G, et al. Mycobacterium tuberculosis inhibition of phagolysosome biogenesis and autophagy as a host defence mechanism. Cell Microbiol. 2006;8:719-27.

42. Starr T, Sun Y, Wilkins N, Storrie B. Rab33b and Rab6 Are functionally overlapping regulators of Golgi homeostasis and trafficking. Traffic. 2010; DOI:10.1111/j.1600-0854.2010.01051.

43. Sun LM, Cheng AX, Wu XZ, Zhang HJ, Lou HX. Synergistic mechanisms of retigeric acid $B$ and azoles against Candida albicans. J Appl Microbiol. 2010;108:341-8.

44. Keane J, Balcewicz-Sablinska MK, Remold HG, Chupp GL, Meek BB, Fenton MJ, et al. Infection by Mycobacterium tuberculosis promotes human alveolar macrophage apoptosis. Infect Immun. 1997;65:298-304.

45. Kroemer G, Galluzzi L, Vandenabeele P, Abrams J, Alnemri ES, Baehrecke EH, et al. Classification of cell death: recommendations of the Nomenclature Committee on Cell Death 2009. Cell Death Differ. 2009;16:3-11.

46. Fink SL, Cookson BT. Apoptosis, pyroptosis, and necrosis: mechanistic description of dead and dying eukaryotic cells. Infect Immun. 2005;73:1907-16.

47. Arcila ML, Sanchez MD, Ortiz B, Barrera LF, Garcia LF, Rojas M. Activation of apoptosis, but not necrosis, during Mycobacterium tuberculosis infection correlated with decreased bacterial growth: role of TNF-alpha, IL10, caspases and phospholipase A2. Cell Immunol. 2007;249:80-93.

48. Gil DP, Leon LG, Correa LI, Maya JR, Paris SC, Garcia LF, et al. Differential induction of apoptosis and necrosis in monocytes from patients with tuberculosis and healthy control subjects. J Infect Dis. 2004;189:2120-8.

49. Sanchez MD, Garcia Y, Montes C, Paris SC, Rojas M, Barrera LF, et al. Functional and phenotypic changes in monocytes from patients with tuberculosis are reversed with treatment. Microbes Infect. 2006;8:2492-500.

50. Rojas M, Barrera LF, Puzo G, Garcia LF. Differential induction of apoptosis by virulent Mycobacterium tuberculosis in resistant and susceptible murine macrophages: role of nitric oxide and mycobacterial products. J Immunol. 1997;159:1352-61.

51. Rojas M, Barrera LF, Garcia LF. Induction of apoptosis in murine macrophages by Mycobacterium tuberculosis is reactive oxygen intermediates-independent. Biochem Biophys Res Commun. 1998;247:436-42. 
52. Rojas M, Olivier M, Gros P, Barrera LF, Garcia LF. TNFalpha and IL-10 modulate the induction of apoptosis by virulent Mycobacterium tuberculosis in murine macrophages. J Immunol. 1999;162:6122-31.

53. Rojas M, Olivier M, Garcia LF. Activation of JAK2/STAT1alpha-dependent signaling events during Mycobacterium tuberculosis-induced macrophage apoptosis. Cell Immunol. 2002;217:58-66.

54. Arias M, Rojas M, Zabaleta J, Rodriguez JI, Paris SC, Barrera LF, et al. Inhibition of virulent Mycobacterium tuberculosis by $\mathrm{Bcg}(\mathrm{r})$ and $\mathrm{Bcg}(\mathrm{s})$ macrophages correlates with nitric oxide production. J Infect Dis. 1997;176:1552-8.

55. Nigou J, Gilleron M, Rojas M, Garcia LF, Thurnher M, Puzo G. Mycobacterial lipoarabinomannans: modulators of dendritic cell function and the apoptotic response. Microbes Infect. 2002;4:945-53.

56. Calzada-Wack JC, Frankenberger M, Ziegler-Heitbrock HW. Interleukin-10 drives human monocytes to CD16 positive macrophages. J Inflamm. 1996;46:78-85.

57. Medina E, Rogerson BJ, North RJ. The Nramp1 antimicrobial resistance gene segregates independently of resistance to virulent Mycobacterium tuberculosis. Immunology. 1996;88:479-81.

58. Medina E, North RJ. The Bcg gene (Nramp1) does not determine resistance of mice to virulent Mycobacterium tuberculosis. Ann NY Acad Sci. 1996;797:257-9.

59. Medina E, North RJ. Resistance ranking of some common inbred mouse strains to Mycobacterium tuberculosis and relationship to major histocompatibility complex haplotype and Nramp1 genotype. Immunology. 1998;93:270-4.

60. Medina E, North RJ. Genetically susceptible mice remain proportionally more susceptible to tuberculosis after vaccination. Immunology. 1999;96:16-21.

61. Medina E, Ryan L, LaCourse R, North RJ. Superior virulence of Mycobacterium bovis over Mycobacterium tuberculosis (Mtb) for Mtb-resistant and Mtb-susceptible mice is manifest as an ability to cause extrapulmonary disease. Tuberculosis (Edinb ). 2006;86:20-7.

62. Boyartchuk V, Rojas M, Yan BS, Jobe O, Hurt N, Dorfman DM, et al. The host resistance locus sst1 controls innate immunity to Listeria monocytogenes infection in immunodeficient mice. J Immunol. 2004;173:5112-20.

63. Vidal SM, Malo D, Vogan K, Skamene E, Gros P. Natural resistance to infection with intracellular parasites: isolation of a candidate for Bcg. Cell. 1993;73:469-85.

64. Kramnik I, Demant P, Bloom BB. Susceptibility to tuberculosis as a complex genetic trait: analysis using recombinant congenic strains of mice. Novartis Found Symp. 1998;217:120-31.

65. Kramnik I, Dietrich WF, Demant P, Bloom BR. Genetic control of resistance to experimental infection with virulent Mycobacterium tuberculosis. Proc Natl Acad Sci USA. 2000;97:8560-5.

66. Pan H, Yan BS, Rojas M, Shebzukhov YV, Zhou H, Kobzik L, et al. Ipr1 gene mediates innate immunity to tuberculosis. Nature. 2005;434:767-72.

67. Boyartchuk V, Rojas M, Yan BS, Jobe O, Hurt N, Dorfman DM, et al. The host resistance locus sst1 controls innate immunity to Listeria monocytogenes infection in immunodeficient mice. J Immunol. 2004;173:5112-20.

68. Yan BS, Kirby A, Shebzukhov YV, Daly MJ, Kramnik I. Genetic architecture of tuberculosis resistance in a mouse model of infection. Genes Immun. 2006;7:201-10.

69. Tosh K, Campbell SJ, Fielding K, Sillah J, Bah B, Gustafson P, et al. Variants in the SP110 gene are associated with genetic susceptibility to tuberculosis in West Africa. Proc Natl Acad Sci USA. 2006;103:10364-8.

70. Babb C, Keet EH, van Helden PD, Hoal EG. SP110 polymorphisms are not associated with pulmonary tuberculosis in a South African population. Hum Genet. 2007;121:521-2.

71. Szeszko JS, Healy B, Stevens H, Balabanova Y, Drobniewski F, Todd JA, et al. Resequencing and association analysis of the SP110 gene in adult pulmonary tuberculosis. Hum Genet. 2007;121:155-60.

72. Thye T, Browne EN, Chinbuah MA, Gyapong J, Osei I, Owusu-Dabo E, et al. No associations of human pulmonary tuberculosis with Sp110 variants. J Med Genet. 2006;43:e32.

73. Balaji KN, Goyal G, Narayana Y, Srinivas M, Chaturvedi R, Mohammad S. Apoptosis triggered by Rv1818c, a PE family gene from Mycobacterium tuberculosis is regulated by mitochondrial intermediates in T cells. Microbes Infect. 2007:9:271-81.

74. Balcewicz-Sablinska MK, Keane J, Kornfeld H, Remold HG. Pathogenic Mycobacterium tuberculosis evades apoptosis of host macrophages by release of TNF$\mathrm{R} 2$, resulting in inactivation of TNF-alpha. J Immunol. 1998;161:2636-41.

75. Ciaramella A, Martino A, Cicconi R, Colizzi V, Fraziano M. Mycobacterial 19-kDa lipoprotein mediates Mycobacterium tuberculosis-induced apoptosis in monocytes/ macrophages at early stages of infection. Cell Death Differ. 2000;7:1270-2.

76. Keane J, Remold HG, Kornfeld H. Virulent Mycobacterium tuberculosis strains evade apoptosis of infected alveolar macrophages. J Immunol. 2000;164:2016-20.

77. Lee J, Remold HG, leong MH, Kornfeld H. Macrophage apoptosis in response to high intracellular burden of Mycobacterium tuberculosis is mediated by a novel caspaseindependent pathway. J Immunol. 2006;176:4267-74.

78. Lee J, Hartman M, Kornfeld H. Macrophage apoptosis in tuberculosis. Yonsei Med J. 2009;50:1-11.

79. Li JM, Li N, Zhu DY, Wan LG, He YL, Yang C. Isocitrate lyase from Mycobacterium tuberculosis promotes survival of Mycobacterium smegmatis within macrophage by suppressing cell apoptosis. Chin Med J (Engl ). 2008;121:1114-9.

80. Lopez M, Sly LM, Luu Y, Young D, Cooper H, Reiner NE. The 19-kDa Mycobacterium tuberculosis protein induces macrophage apoptosis through Toll-like receptor-2. J Immunol. 2003;170:2409-16.

81. Mariani F, Goletti D, Ciaramella A, Martino A, Colizzi V, Fraziano M. Macrophage response to Mycobacterium tuberculosis during HIV infection: relationships between macrophage activation and apoptosis. Curr Mol Med. 2001;1:209-16. 
82. Oddo M, Renno T, Attinger A, Bakker T, MacDonald HR, Meylan PR. Fas ligand-induced apoptosis of infected human macrophages reduces the viability of intracellular Mycobacterium tuberculosis. J Immunol. 1998;160:544854.

83. Park JS, Tamayo MH, Gonzalez-Juarrero M, Orme IM, Ordway DJ. Virulent clinical isolates of Mycobacterium tuberculosis grow rapidly and induce cellular necrosis but minimal apoptosis in murine macrophages. J Leukoc Biol. 2006;79:80-6.

84. Perskvist N, Long M, StendahI O, Zheng L. Mycobacterium tuberculosis promotes apoptosis in human neutrophils by activating caspase- 3 and altering expression of Bax/ $\mathrm{Bcl}-\mathrm{xL}$ via an oxygen-dependent pathway. J Immunol. 2002;168:6358-65.

85. Persson A, Blomgran-Julinder R, Eklund D, Lundstrom C, Stendahl O. Induction of apoptosis in human neutrophils by Mycobacterium tuberculosis is dependent on mature bacterial lipoproteins. Microb Pathog. 2009;47:143-50.

86. Torchinsky MB, Garaude J, Blander JM. Infection and apoptosis as a combined inflammatory trigger. Curr Opin Immunol. 2010;22:55-62.

87. Placido R, Mancino G, Amendola A, Mariani F, Vendetti $\mathbf{S}$, Piacentini $\mathbf{M}$, et al. Apoptosis of human monocytes/ macrophages in Mycobacterium tuberculosis infection. $\mathrm{J}$ Pathol. 1997;181:31-8.

88. Placido R, Auricchio G, Falzoni S, Battistini L, Colizzi V, Brunetti E, et al. P2X(7) purinergic receptors and extracellular ATP mediate apoptosis of human monocytes/ macrophages infected with Mycobacterium tuberculosis reducing the intracellular bacterial viability. Cell Immunol. 2006;244:10-8.

89. Rajavelu P, Das SD. A correlation between phagocytosis and apoptosis in THP-1 cells infected with prevalent strains of Mycobacterium tuberculosis. Microbiol Immunol. 2007;51:201-10.

90. Rajavelu P, Das SD. Expression of co-stimulatory molecules B7.1 \& B7.2 on macrophages infected with various strains of Mycobacterium tuberculosis \& its influence on T-cell apoptosis. Indian J Med Res. 2008;127:388-94.

91. Randhawa AK, Ziltener HJ, Stokes RW. CD43 controls the intracellular growth of Mycobacterium tuberculosis through the induction of TNF-alpha-mediated apoptosis. Cell Microbiol. 2008;10:2105-17.

92. Rios-Barrera VA, Campos-Pena V, Aguilar-Leon $\mathrm{D}$, Lascurain LR, Meraz-Rios MA, Moreno $\mathrm{J}$, et al. Macrophage and $\mathrm{T}$ lymphocyte apoptosis during experimental pulmonary tuberculosis: their relationship to mycobacterial virulence. Eur J Immunol. 2006;36:345-53.

93. Velmurugan K, Chen B, Miller JL, Azogue S, Gurses $\mathrm{S}$, Hsu T, et al. Mycobacterium tuberculosis nuoG is a virulence gene that inhibits apoptosis of infected host cells. PLoS Pathog. 2007;3:e110.

94. Schaible UE, Winau F, Sieling PA, Fischer K, Collins HL, Hagens $\mathrm{K}$, et al. Apoptosis facilitates antigen presentation to T lymphocytes through MHC-I and CD1 in tuberculosis. Nat Med. 2003;9:1039-46.

95. Molloy A, Laochumroonvorapong P, Kaplan G. Apoptosis, but not necrosis, of infected monocytes is coupled with killing of intracellular bacillus Calmette-Guerin. J Exp Med. 1994;180:1499-509.

96. Davis JM, Ramakrishnan L. The role of the granuloma in expansion and dissemination of early tuberculous infection. Cell. 2009;136:37-49.

97. Rubin EJ. The granuloma in tuberculosis--friend or foe? $\mathrm{N}$ Engl J Med. 2009;360:2471-3.

98. Pedroza-Gonzalez A, Garcia-Romo GS, Aguilar-Leon D, Calderon-Amador J, Hurtado-Ortiz R, OrozcoEstevez $\mathrm{H}$, et al. In situ analysis of lung antigenpresenting cells during murine pulmonary infection with virulent Mycobacterium tuberculosis. Int J Exp Pathol. 2004;85:135-45.

99. Gil D, Garcia LF, Rojas M. Modulation of macrophage apoptosis by antimycobacterial therapy: physiological role of apoptosis in the control of Mycobacterium tuberculosis. Toxicol Appl Pharmacol. 2003;190:111-9.

100. Adibhatla RM, Hatcher JF. Phospholipase A(2), reactive oxygen species, and lipid peroxidation in CNS pathologies. BMB Rep. 2008;41:560-7.

101. Artwohl M, Lindenmair A, Roden M, WaldhausI WK, Freudenthaler A, Klosner G, et al. Fatty acids induce apoptosis in human smooth muscle cells depending on chain length, saturation, and duration of exposure. Atherosclerosis. 2008;202:351-62.

102. Atsumi G, Tajima M, Hadano A, Nakatani Y, Murakami M, Kudo I. Fas-induced arachidonic acid release is mediated by $\mathrm{Ca} 2+$-independent phospholipase $\mathrm{A} 2$ but not cytosolic phospholipase A2, which undergoes proteolytic inactivation. J Biol Chem. 1998;273:13870-7.

103. Balboa MA, Balsinde J. Oxidative stress and arachidonic acid mobilization. Biochim Biophys Acta. 2006;1761:385-91.

104. Kanai K, Kondo E. Phospholipase A2-induced antimycobacterial activity in the membrane fraction obtained from peritoneal exudate cells of guinea pigs. Jpn J Med Sci Biol. 1980;33:87-101.

105. Baek SH, Takayama K, Kudo I, Inoue K, Lee HW, Do JY, et al. Detection and characterization of extracellular phospholipase A2 in pleural effusion of patients with tuberculosis. Life Sci. 1991;49:1095-102.

106. Duan L, Gan H, Arm J, Remold HG. Cytosolic phospholipase A2 participates with TNF-alpha in the induction of apoptosis of human macrophages infected with Mycobacterium tuberculosis H37Ra. J Immunol. 2001;166:7469-76.

107. Akaki T, Tomioka H, Shimizu T, Dekio S, Sato K. Comparative roles of free fatty acids with reactive nitrogen intermediates and reactive oxygen intermediates in expression of the anti-microbial activity of macrophages against Mycobacterium tuberculosis. Clin Exp Immunol. 2000;121:302-10.

108. Ziegler-Heitbrock HW, Passlick B, Flieger D. The monoclonal antimonocyte antibody My4 stains B lymphocytes and two distinct monocyte subsets in human peripheral blood. Hybridoma. 1988;7:521-7.

109. PasslickB, Flieger D, Ziegler-HeitbrockHW. Identification and characterization of a novel monocyte subpopulation in human peripheral blood. Blood. 1989;74:2527-34. 
110. Ziegler-Heitbrock HW, Schlag R, Flieger D, Thiel E. Favorable response of early stage B CLL patients to treatment with IFN-alpha 2. Blood. 1989;73:1426-30.

111. Ziegler-Heitbrock HW. The biology of the monocyte system. Eur J Cell Biol. 1989;49:1-12.

112. Ancuta P, Rao R, Moses A, Mehle A, Shaw SK, Luscinskas FW, et al. Fractalkine preferentially mediates arrest and migration of CD16+ monocytes. J Exp Med. 2003;197:1701-7.

113. Martinez FO. The transcriptome of human monocyte subsets begins to emerge. J Biol. 2009;8:99.

114. Skrzeczynska-Moncznik J, Bzowska M, Loseke S, Grage-Griebenow E, Zembala M, Pryjma J. Peripheral blood CD14high CD16+ monocytes are main producers of IL-10. Scand J Immunol. 2008;67:152-9.

115. Belge KU, Dayyani F, Horelt A, Siedlar M, Frankenberger $\mathbf{M}$, Frankenberger $\mathbf{B}$, et al. The proinflammatory CD14+CD16+DR++ monocytes are a major source of TNF. J Immunol. 2002;168:3536-42.

116. Hanai H, lida T, Takeuchi K, Watanabe F, Yamada M, Kikuyama M, et al. Adsorptive depletion of elevated proinflammatory CD14+CD16+DR++ monocytes in patients with inflammatory bowel disease. Am J Gastroenterol. 2008;103:1210-6.

117. Capsoni F, Minonzio F, Ongari AM, Carbonelli V, Galli A, Zanussi C. IL-10 up-regulates human monocyte phagocytosis in the presence of IL-4 and IFN-gamma. J Leukoc Biol. 1995:58:351-8.

118. Saleh MN, Goldman SJ, LoBuglio AF, Beall AC, Sabio $\mathrm{H}$, McCord MC, et al. CD16+ monocytes in patients with cancer: spontaneous elevation and pharmacologic induction by recombinant human macrophage colonystimulating factor. Blood. 1995;85:2910-7.

119. Fingerle G, Pforte A, Passlick B, Blumenstein M, Strobel M, Ziegler-Heitbrock HW. The novel subset of CD14+/CD16+ blood monocytes is expanded in sepsis patients. Blood. 1993;82:3170-6.

120. Rothe G, Gabriel H, Kovacs E, Klucken J, Stohr J, Kindermann W, et al. Peripheral blood mononuclear phagocyte subpopulations as cellular markers in hypercholesterolemia. Arterioscler Thromb Vasc Biol. 1996;16:1437-47.

121. Tanaka M, Honda J, Imamura Y, Shiraishi K, Tanaka K, Oizumi K. Surface phenotype analysis of CD16+ monocytes from leukapheresis collections for peripheral blood progenitors. Clin Exp Immunol. 1999;116:57-61.

122. Moniuszko M, Bodzenta-Lukaszyk A, Kowal K, Lenczewska D, Dabrowska M. Enhanced frequencies of CD14++CD16+, but not CD14+CD16+, peripheral blood monocytes in severe asthmatic patients. Clin Immunol. 2009;130:338-46.

123. Grage-Griebenow E, Lorenzen D, Fetting R, Flad HD, Ernst M. Phenotypical and functional characterization of Fc gamma receptor I (CD64)-negative monocytes, a minor human monocyte subpopulation with high accessory and antiviral activity. Eur J Immunol. 1993;23:3126-35.

124. Ziegler-Heitbrock L. The CD14+CD16+ blood monocytes: their role in infection and inflammation. J Leukoc Biol. 2007;81:584-92.
125. Weber C, Belge KU, von HP, Draude G, Steppich B, Mack M, et al. Differential chemokine receptor expression and function in human monocyte subpopulations. J Leukoc Biol. 2000;67:699-704.

126. Geissmann F, Jung S, Littman DR. Blood monocytes consist of two principal subsets with distinct migratory properties. Immunity. 2003;19:71-82.

127. Baeten D, Boots AM, Steenbakkers PG, Elewaut D, Bos E, Verheijden GF, et al. Human cartilage gp-39+,CD16+ monocytes in peripheral blood and synovium: correlation with joint destruction in rheumatoid arthritis. Arthritis Rheum. 2000;43:1233-43.

128. Schlitt A, Heine GH, Blankenberg S, Espinola-Klein C, Dopheide JF, Bickel C, et al. CD14+CD16+ monocytes in coronary artery disease and their relationship to serum TNF-alpha levels. Thromb Haemost. 2004;92:419-24.

129. Ziegler-Heitbrock HW, Strobel M, Kieper D, Fingerle G, Schlunck T, Petersmann I, et al. Differential expression of cytokines in human blood monocyte subpopulations. Blood. 1992;79:503-11.

130. Ancuta P, Liu KY, Misra V, Wacleche VS, Gosselin $A$, Zhou $X$, et al. Transcriptional profiling reveals developmental relationship and distinct biological functions of CD16+ and. BMC Genomics. 2009;10:403.

131. Munn DH, Bree AG, Beall AC, Kaviani MD, Sabio $\mathbf{H}$, Schaub RG, et al. Recombinant human macrophage colony-stimulating factor in nonhuman primates: selective expansion of a CD16+ monocyte subset with phenotypic similarity to primate natural killer cells. Blood. 1996;88:1215-24.

132. Skinner NA, Maclsaac CM, Hamilton JA, Visvanathan K. Regulation of toll-like receptor (TLR)2 and TLR4 on CD14dimCD16+ monocytes in response to sepsis-related antigens. Clin Exp Immunol. 2005;141:270-8.

133. Rouzaut A, Subira ML, de MC, Domingo-de-Miguel E, Gonzalez A, Santiago E, et al. Co-expression of inducible nitric oxide synthase and arginases in different human monocyte subsets. Apoptosis regulated by endogenous NO. Biochim Biophys Acta. 1999;1451:319-33.

134. Zhao C, Zhang H, Wong WC, Sem X, Han H, Ong $\mathrm{SM}$, et al. Identification of novel functional differences in monocyte subsets using proteomic and transcriptomic methods. J Proteome Res.2009; 8:4028-38.

135. Mobley JL, Leininger M, Madore S, Baginski TJ, Renkiewicz R. Genetic evidence of a functional monocyte dichotomy. Inflammation. 2007;30:189-97.

136. Scherberich JE, Nockher WA. CD14++ monocytes, CD14+/CD16+ subset and soluble CD14 as biological markers of inflammatory systemic diseases and monitoring immunosuppressive therapy. Clin Chem Lab Med. 1999;37:209-13.

137. Ziegler-Heitbrock HW, Strobel M, Fingerle G, Schlunck T, Pforte A, Blumenstein M, et al. Small (CD14+/CD16+) monocytes and regular monocytes in human blood. Pathobiology. 1991;59:127-30.

138. Nockher WA, Scherberich JE. Expanded CD14+ CD16+ monocyte subpopulation in patients with acute and chronic infections undergoing hemodialysis. Infect Immun. 1998;66:2782-90. 
139. Thomas R, Lipsky PE. Human peripheral blood dendritic cell subsets. Isolation and characterization of precursor and mature antigen-presenting cells. J Immunol. $1994 ; 153: 4016-28$.

140. Moreno-Altamirano MM, Aguilar-Carmona I, SanchezGarcia FJ. Expression of GM1, a marker of lipid rafts, defines two subsets of human monocytes with differential endocytic capacity and lipopolysaccharide responsiveness. Immunology. 2007;120:536-43.

141. Sanchez-Torres C, Garcia-Romo GS, Cornejo-Cortes MA, Rivas-Carvalho A, Sanchez-Schmitz G. CD16+ and. Int Immunol. 2001;13:1571-81.

142. Rivas-Carvalho A, Meraz-Rios MA, Santos-Argumedo L, Bajana S, Soldevila G, Moreno-Garcia ME, et al.
CD16+ human monocyte-derived dendritic cells matured with different and unrelated stimuli promote similar allogeneic Th2 responses: regulation by pro- and antiinflammatory cytokines. Int Immunol. 2004;16:1251-63.

143. Vanham G, Edmonds K, Qing L, Hom D, Toossi $Z$, Jones B, et al. Generalized immune activation in pulmonary tuberculosis: co-activation with HIV infection. Clin Exp Immunol. 1996;103:30-4.

144. Barcelos W, Martins-Filho OA, Guimaraes TM, Oliveira $\mathrm{MH}$, Spindola-de-Miranda $\mathrm{S}$, Carvalho BN, et al. Peripheral blood mononuclear cells immunophenotyping in pulmonary tuberculosis patients before and after treatment. Microbiol Immunol. 2006;50:597-605. 